\title{
Organophosphorus Flame Retardants (OPFR): Neurotoxicity
}

\author{
Mohamed B. Abou-Donia ${ }^{1 *}$ Mohamed Salama $^{2}$, Mohamed Elgamal' ${ }^{2}$ Islam Elkholi ${ }^{2,3}$, Qiangwei Wang ${ }^{1,4}$ \\ ${ }^{1}$ Department of Pharmacology and Cancer Biology, Duke University Medical Center, Durham, North Carolina, USA \\ ${ }^{2}$ Medical Experimental Research Center (MERC), Faculty of Medicine, Mansoura University, Mansoura, Egypt \\ ${ }^{3}$ Center for Aging and Associated Diseases (CAAD), Zewail City of Science and Technology, Giza \\ ${ }^{4}$ Zhejiang University, China
}

*Corresponding author: Mohamed B. Abou-Donia, Department of Pharmacology and Cancer Biology, Duke University Medical Center, Durham, North Carolina 277, USA, Tel: +919-68422/ Fax: 919-681-822, E-mail: donia@duke.edu

Citation: Abou-Donia, M.B., et al. Organophosphorus Flame Retardants (OPFR): Neurotoxicity. (2016) J Environ Health Sci 2(1): $1-30$

Received date: July 07, 2015

Accepted date: May 05, 2016

Published date: May 11, 2016

DOI: $10.15436 / 2378-6841.16 .022$

\begin{abstract}
Organophosphorus flame retardants (OPFRs) are used as additives in plasticizers, foams, hydraulic fluids, anti-foam agents, and coatings for electronic components/devices to inhibit flames. These chemicals were developed and used as flame retardants because of environmental and health concerns of previously used brominated and chlorinated flame retardants (FRs). OPCFRs are divided into five main groups: organophosphates, organophosphonates, organophosphinates, organoposphine oxide, and organophosphites. Most of OPFRs are organophosphate esters that are further classified into the following five groups: 1. Aliphatic, 2. Brominated aliphatic, 3. Chlorinated aliphatic, 4. Aromatic-aliphatic, and 5. Aromatic phosphates. These OPFRs have the following neurotoxic actions: 1. Cholinergic Neurotoxicity, 2. Organophosphate-Induced Delayed Neurotoxicity (OPIDN), and 3. Organophosphate-Induced Chronic Neurotoxicity (OPICN) in addition to being endocrine disruptors. OPFRs have very low cholinergic neurotoxicity and this effect does not pose significant health hazards to adults or children. On the other hand, some OPFRs have shown to cause OPIDN that is a delayed central-peripheral axonopathy, characterized by neuronal cell death of the lower brain regions, spinal cord and peripheral nervous systems, leading to long-term neuronal injury. OPICN is characterized by neuronal cell death in the cortex, hippocampus campus and cerebellum and spinal cord. Finally, OPCFRs act as endocrine disrupters, that affect many functions of the body such thyroid glands and reproductive functions, and may be involved in the development of diabetes and cancer. Residues of these OPCFRs are widespread in the environment, home and workplaces. These chemicals adversely affect human health, especially for vulnerable population such as the elderly, pregnant women, fetuses, and children. Because some OPFRs cause neuronal cell death in the brain and spinal cord that do not repair as well as act as endocrine disrupters they may lead to permanent functional deficits such obesity, memory impairment, decreased motor skill and even more serious diseases such as diabetes and cancer. Because recent reports have accredited FRs for significant decrease in building fires, it is important to balance the risk and benefits of FRs and to use only the safest available FRs including OPFRs.
\end{abstract}

\section{Introduction}

There are over 80,000 chemicals in use today including flame retardants. Flame retardants (FRs) are chemicals added to materials, for the purpose of inhibiting flames. FRs can be classified according to their binding into two types: reactive or additive OPFRs are classified (WHO 1997, Fisk et al., 2003) into two types: The first type is reactive OCPFRs, which are built into a polymer molecule and has limited loss due to their chemical binding. The second type is the additive PFRs, which are mixed into the polymer and continually lost during the lifetime of the treated product resulting in decrease in the flame retardant properties (WHO, 1997; Van der Veen I., De Boer J. 2012). (WHO, 1997 The reactive FRs, are reactive components chemically built into a polymer molecule). This type has a limited loss because of their chemical binding (Fisk et al., 2003). The additive FRs is mixed into the poly- 
mer (WHO, 1997). In the additive FRs type there is continuous decrease in concentration during the lifetime of the treated product and subsequent decrease in the flame retardant properties (Fisk et al., 2003). Mineral flame retardants are typically additive while organohalogen flame retardants and organophosphorus flame retardants (OPFRs) can be either reactive or additive. Additive FRs is applied to a wide range of materials, to slow combustion process (Ellis et al., 2007). Chemically, plastics are materials which consist of synthetic or naturally based macromolecular organic compounds. Additives are added to plastics to improve material properties according to the targeted use. These additives may influence mechanical properties (e.g., plasticizers), or added for safety aspects (e.g., fire protection) (Wensing et al., 2005).

\section{Phosphorus Compounds}

Phosphorus, "P", atomic number 15, atomic weight 30.97, belongs to Group V of the periodic table of the elements. Phosphorus is not found free in nature and is almost always occurs in the fully oxidized state as phosphate (Table 1). The electronic structure of the phosphorus atom is $1 s^{2} 2 s^{2} 2 p^{6} 3 p^{2} 3 p^{3}$ with three unpaired electrons in the outer 3 orbitals that are available for bonding. Phosphorus atom can be formally trivalent or pentavalent, using only three or all five electrons in the outer $\mathrm{M}$ shell, respectively. Pentavalent organophosphorus compounds, such as phosphorus oxychloride $\left(\mathrm{POCl}_{3}\right)$ has tetrahedral configuration. Whereas tri-substituted phosphorus acid esters, such as phosphorus trichloride $\left(\mathrm{PCl}_{3}\right)$ has a pyramidal configuration. Most synthetic organophosphorus compounds are pentavalent. Organophosphorus compounds are used as insecticides, acaricides, nematocides, insect chemosterilants, fungicides, herbicides, nematocides, insect repellants, nerve agents, pharmaceuticals, and as flame retardants (Abou-Donia, 1992). Trivalent compounds include phosphites that are used as antioxidants, defoliants, and flame retardants.

Table 1: PHOSPHORUS ATOM AND ORGANOPHOSPHORUS COMPOUNDS

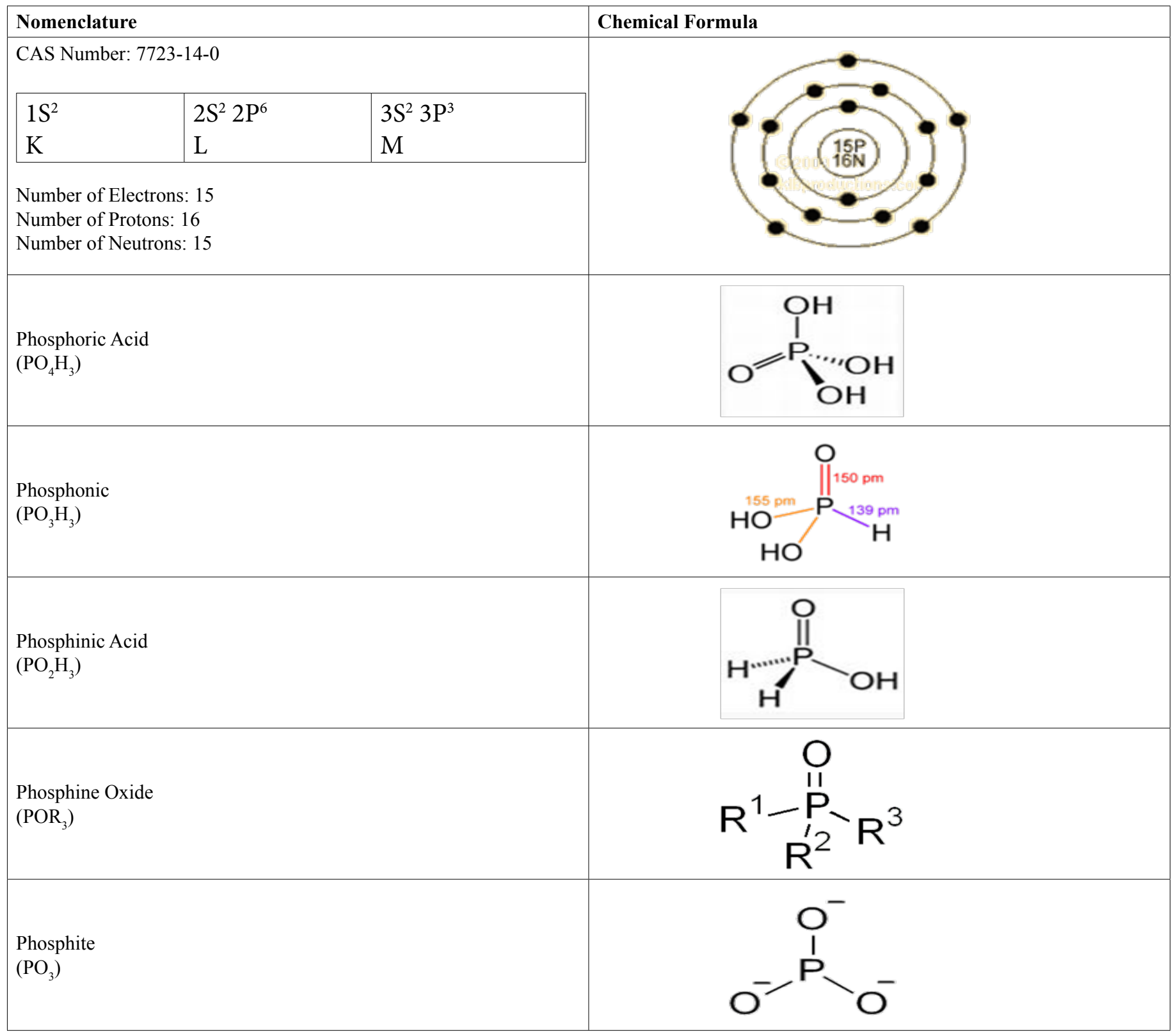




\section{Organophosphorus flame retardants (OPFRs)}

Because of environmental and health concerns about Brominated Flame Retardants (BFRs), such as Polybrominated Diphenyl Ethers (PBDEs), organophosphorus flame retardants (OPFRs) were developed. Most of these chemicals are organophosphate esters. These compounds are used as flame retardant additives in plasticizers, foams, hydraulic fluids, anti-foam agents, u coatings for electronic components/devices, furniture, textile, electronics, construction, vehicle and petroleum industries (Marklund et al., 2003). Similar to brominated flame retardant compounds, the increased use of OPFRs has caused concerns regarding their adverse effects on the environment as well as animal and human health. Furthermore, studies have shown that indoor air and dust had concentrations of OPFRs higher than that of PBDEs (Stapleton et al., 2009). In particular, major concern was the potential carcinogenic, neurological effects and endocrine disruption of these compound (Betts, 2007; Waaijers et al., 2013).

OPs are widely utilized as flame retardants, plasticizers and anti-foaming agents in a variety of industries, including plastics, Because OPFRs are frequently present as additives rather than chemically bonded to materials, they are easily released to different environmental compartments via volatilization, leaching and/or abrasion (Carlsson et al., 2000; der Veen and de Boer, 2012). Meanwhile, due to the need for rapid BFR substitution, many of these OPs are already being marketed, although their environmental behavior and toxicological effects were not properly assessed (Dishaw et al., 2011).

\section{Classification of OPFRs}

OPFRs are divided into five main groups: organophosphates (Tables 2-6), organophosphonates (Table 7), organophosphinates (Table 8), organoposphine oxide (Table 9) organophosphites (Table 10).

\section{Organophosphates}

1.1 Aliphatic organophosphate flame retardants: listed in Table 2, e.g., tris(2-butoxyethyl) phosphate (TBOEP), dimethyl phosphate, trimethylphosphate, diethyl phosphate (mono \& di-), t riethyl phosphate, triisopropyl phosphate, tripropyl phosphate, tri-n-butyl phosphate (TnBP), triisobutyl phosphate, tripentyl phosphate, TPP), tris(2-butoxyethyl) phosphate, tris(2-ethylhexyl) phosphate

Table 2 ALIPHATIC PHOSPHATES FLAME RETARDANTS

\begin{tabular}{|c|c|c|c|c|}
\hline \# & CAS & ABBREVIATION & CHEMICAL NOMENCLATURE & CHEMICAL FORMULA \\
\hline 1 & $813-78-5$ & DMP & Dimethyl phosphate & \\
\hline 2 & $512-56-1$ & TMP & Trimethylphosphate & \\
\hline 3 & $598-02-7$ & DEP & Diethyl phosphate (mono \& di-) & \\
\hline 4 & $78-40-0$ & TEP & Triethyl phosphate & \\
\hline 5 & $513-08-6$ & ТРP & TRIPROPYL PHOSPHATE & \\
\hline 6 & $513-02-0$ & TiPP, TiPrP & Triisopropyl phosphate & \\
\hline
\end{tabular}




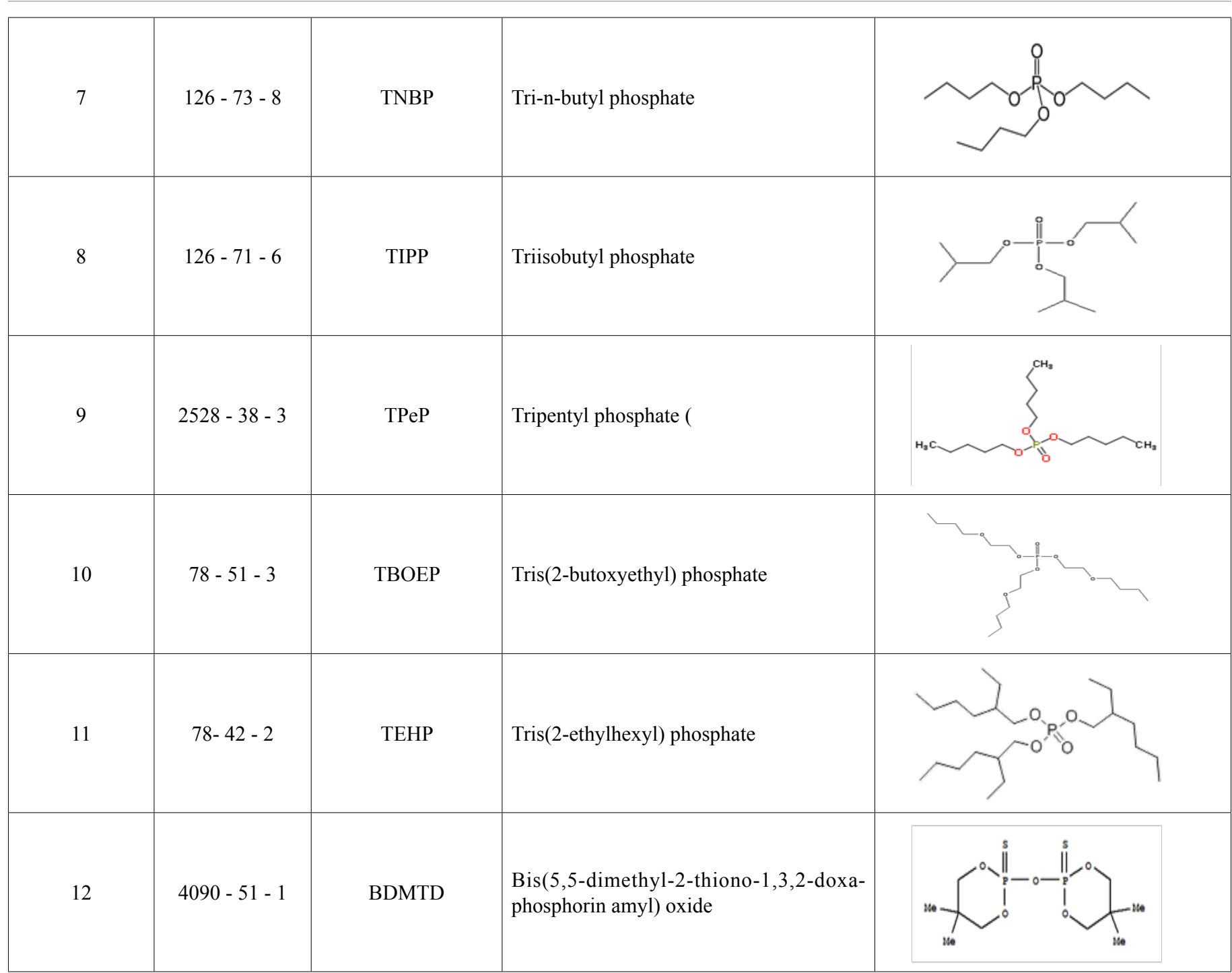

1.2 Brominated aliphatic phosphate flame retardant: listed in Table 3 include tris(tribromooneopentyl)phosphate and tris(2,3-dibromopropyl.

Table 3: BROMO ALIPHATIC PHOSPHATE FLAME RETARDNTS FLAME RETARDANTS

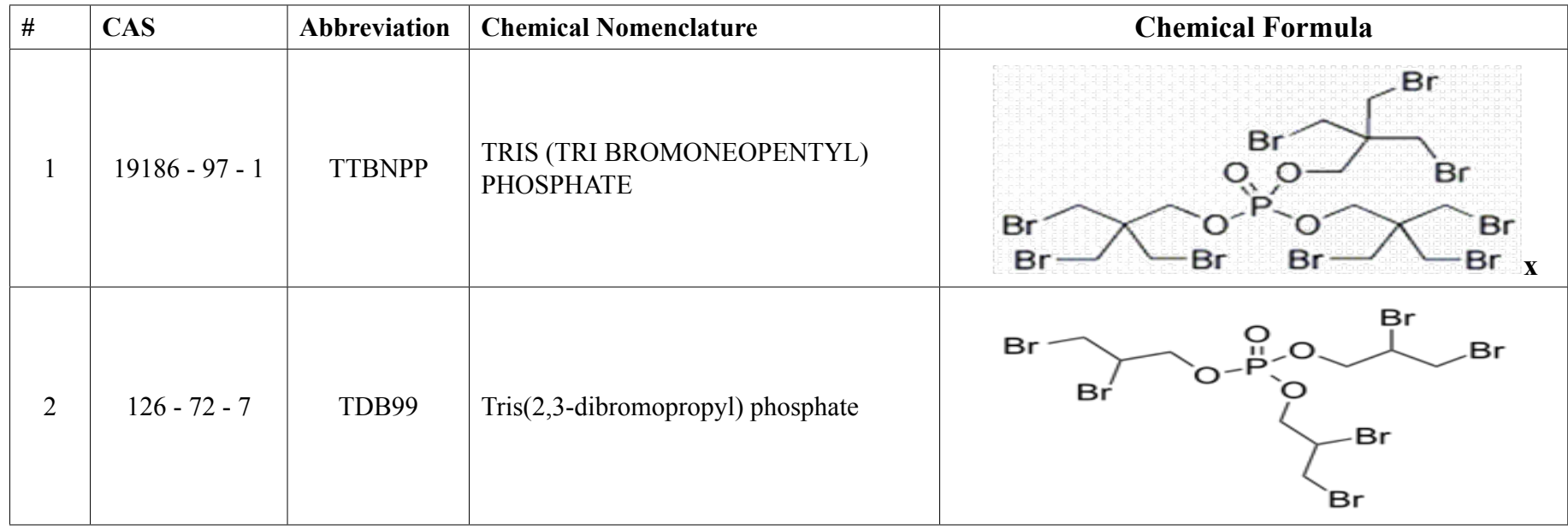

1.3 Chlorinated aliphatic phosphate retardants: listed in Table 4 tris(2-chloroethyl)phosphate, tris(2-dichloropropyl)phosphate; tris(1-chloro-2-propyl)phosphate; 2,2-bis(chloromethyl)-1,3-propanediol bis[bis(2-chloroethyl)phosphate], tris(1-chloro-2-propyl) phosphate, tris(1-Chloro-2-propyl) phosphate (TCPP, TCiPP); Tris(2,3-dichloropropyl)Phosphate;tris(1,3-dichloro-2-propyl)phosphate,2,2-bis(chloromethyl-)trimethylene bis(bis(2-chloroethyl) phosphate, tetrakis(2-chloroethyl). dichlo-isopentyl diphosphate; 
tris(1,3-dichloroisopropyl) phosphate (TDCPP); tris(2-chloroethyl) phosphate (TCEP);and tris(chloropropyl)phosphate (TCPP). TDCPP and these other chlorinated organophosphate flame retardants are all sometimes referred to as "chlorinated tris". To comply with U.S. Flammable Fabrics Act of 1953, TDCPP was used as a flame retardant in children's pajamas until the late 1970s. TDCPP, is primary used as a flame retardants in flexible polyurethane foam for automobiles, upholstered furniture, and some baby products (Marklund et al.2005; Thorvad, 2005; Andersen et al., 2004; Gold et al., 1978). It is also used in rigid polyurethane foam boards used for building insulation (Carignan et al., 2013). In 2011 it was reported that TDCPP was found in about a third of tested baby products (Stapleton et al., 2009).

Table 4: CHLORO ALIPHATIC PHOSPHATES FLAME RETARDANTS

\begin{tabular}{|c|c|c|c|c|}
\hline & CAS NUMBER & ABBREVIATION & CHEMICAL NOMENCLATURE & CHEMICAL FORMULA \\
\hline 1 & $115-96-8$ & Tcep & Tris(2-chloroethyl)phosphate & \\
\hline 2 & $78-43-3$ & TDCPP & $\begin{array}{l}\text { Tris(2,3-dichloropropyl) } \\
\text { phosphate }\end{array}$ & \\
\hline 4 & $38051-10-4$ & ВСМР-ВСЕР & $\begin{array}{l}\text { 2,2-Bis(chloromethyl)-1,3- } \\
\text { propanediol bis[bis(2- } \\
\text { chloroethyl)phosphate]T }\end{array}$ & \\
\hline 5 & $13674-84-5$ & TCPP & Tris(1-chloro-2-propyl) phosphate & \\
\hline 7 & $78-43-3$ & TDCPP & $\begin{array}{l}\text { Tris(2,3-DICHLOROPROPYL) } \\
\text { Phosphate }\end{array}$ & \\
\hline 8 & $13674-87-8$ & TDCTPP & $\begin{array}{l}\text { Tris(1,3-dichloro-2-propyl) } \\
\text { phosphate }\end{array}$ & \\
\hline 9 & $38051-10-4$ & BCMP & $\begin{array}{l}\text { 2,2-bis(chloromethyl-)trimethylen- } \\
\text { ebis(bis(2-chloroethyl)phosphate }\end{array}$ & \\
\hline 10 & $38051-10-4$ & TCDDP & $\begin{array}{l}\text { Tetrakis(2-Chloroethyl) } \\
\text { dichlo-isopentyl diphosphate (V6) }\end{array}$ & \\
\hline
\end{tabular}


1.4 Aromatic-aliphatic phosphate flame retardants: e.g., isopropyl phenyl phosphate, 2-ethylhexyl diphenyl phosphate, isodecyl diphenyl phosphate, and cresyl phosphare isomers.

Table 5: AROMATIC ALIPHATIC PHOSPHATES FLAME RETARDANTS

\begin{tabular}{|l|c|c|l|l|}
\hline$\#$ & CAS \# & ABBREVIATION & CHEMICAL NOMENCLATURE & CHEMICAL FORMULA \\
\hline 1 & $46355-07-1$ & IPPP & Iso-propyll Phenyl Phosphate & \\
\hline 2 & $1241-94-7$ & EDP, DPEHP & 2-Ethylhexyl diphenyl phosphate & \\
\hline 4 & $29761-21-5$ & IDP & Isodecyl diphenyl phosphate & \\
\hline 5 & & & &
\end{tabular}

1.5 Aromatic phosphate retardants: e.g., triphenyl phosphate (TPP), 9, 10-dihydro-9-oxa-10-phospha-phenanthrene-10-oxide, triphenyl phosphate, tricresyl phosphate, bisphenol A bis (diphenylphosphate), cresyl diphenyl phosphate, tri-o-cresyl phosphate, tri-p-cresyl phosphate, polychlorobiphenyl

TABLE 6: AROMATIC ORGANOPHOSPHATES FLAME RETARDANTS

\begin{tabular}{|c|c|c|c|c|}
\hline \# & CAS Number & ABBREVIATION & CHEMICAL NOMENCLATURE & CHEMICAL FORMULA \\
\hline 1 & $35948-25-5$ & & $\begin{array}{l}\text { 9,10-Dihydro-9-oxa-10-phospha- } \\
\text { phenanthrene-10-oxide }\end{array}$ & \\
\hline 2 & $115-86-6$ & TPHP & Triphenyl Phosphate & \\
\hline 3 & $1330-78-5$ & TMPP & Tricresyl phosphate & \\
\hline
\end{tabular}




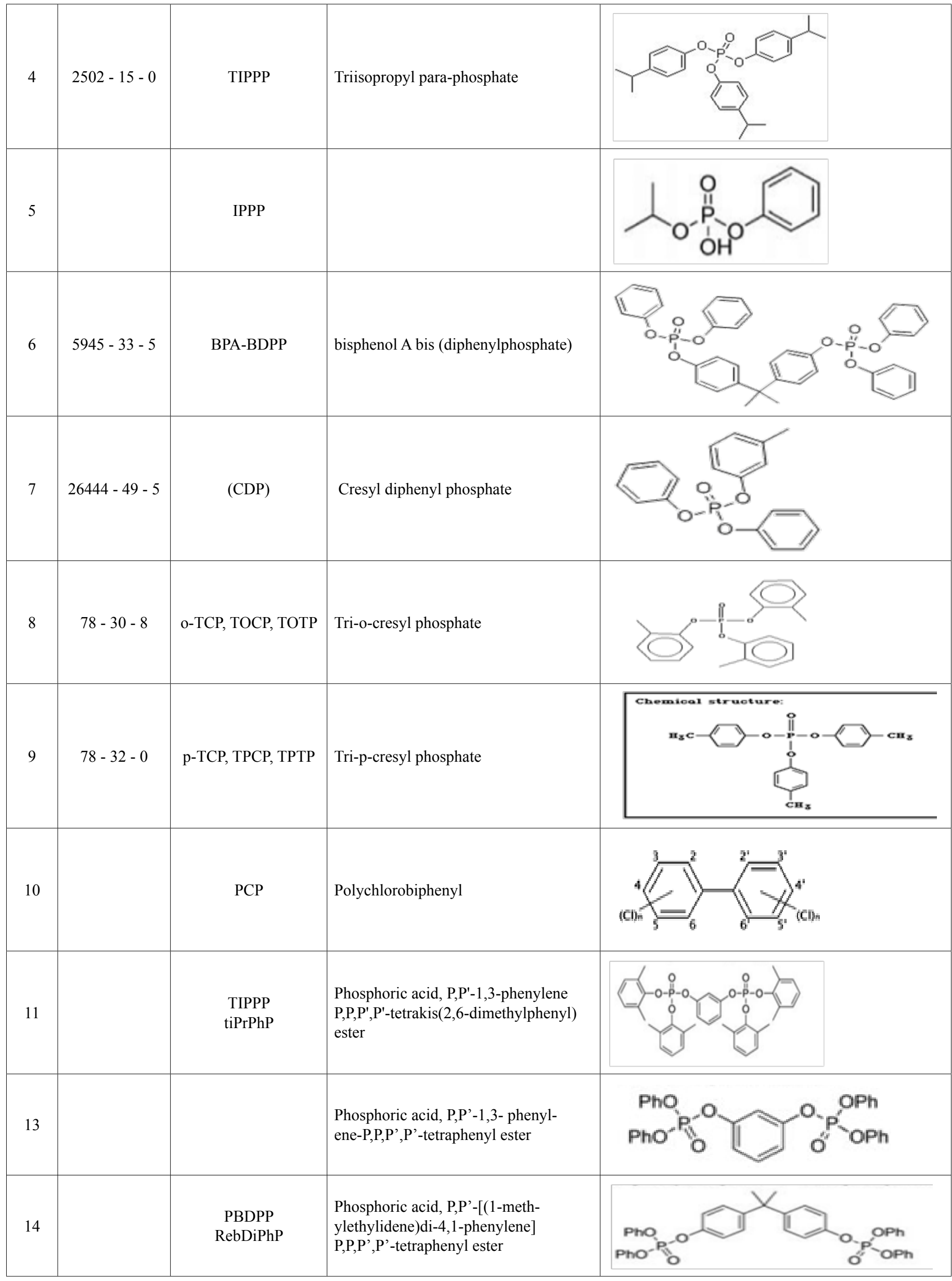




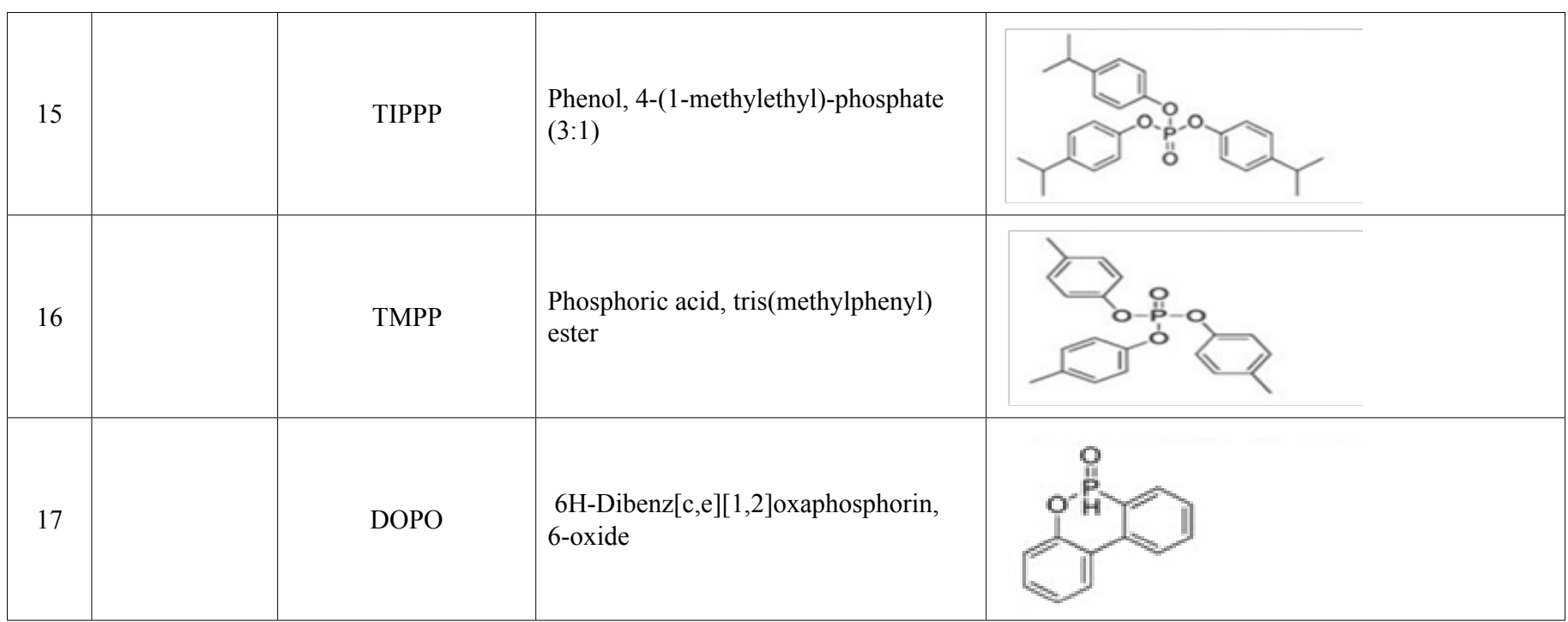

\section{Organophosphonates}

e.g., Dimethyl Phosphonate, Dimethyl Phosphonate, Dimethyl propyl phosphonate, Diethyl ethyl phosphonate, 3-(Dimethylphosphono)propionic acid methylamide and Phosphonic acid, (1-(((2-loroethoxy)(2-chloroethyl)phosphinyl)-oxo)-ethyl

Table 7: Organophosphonate Flame Retardants

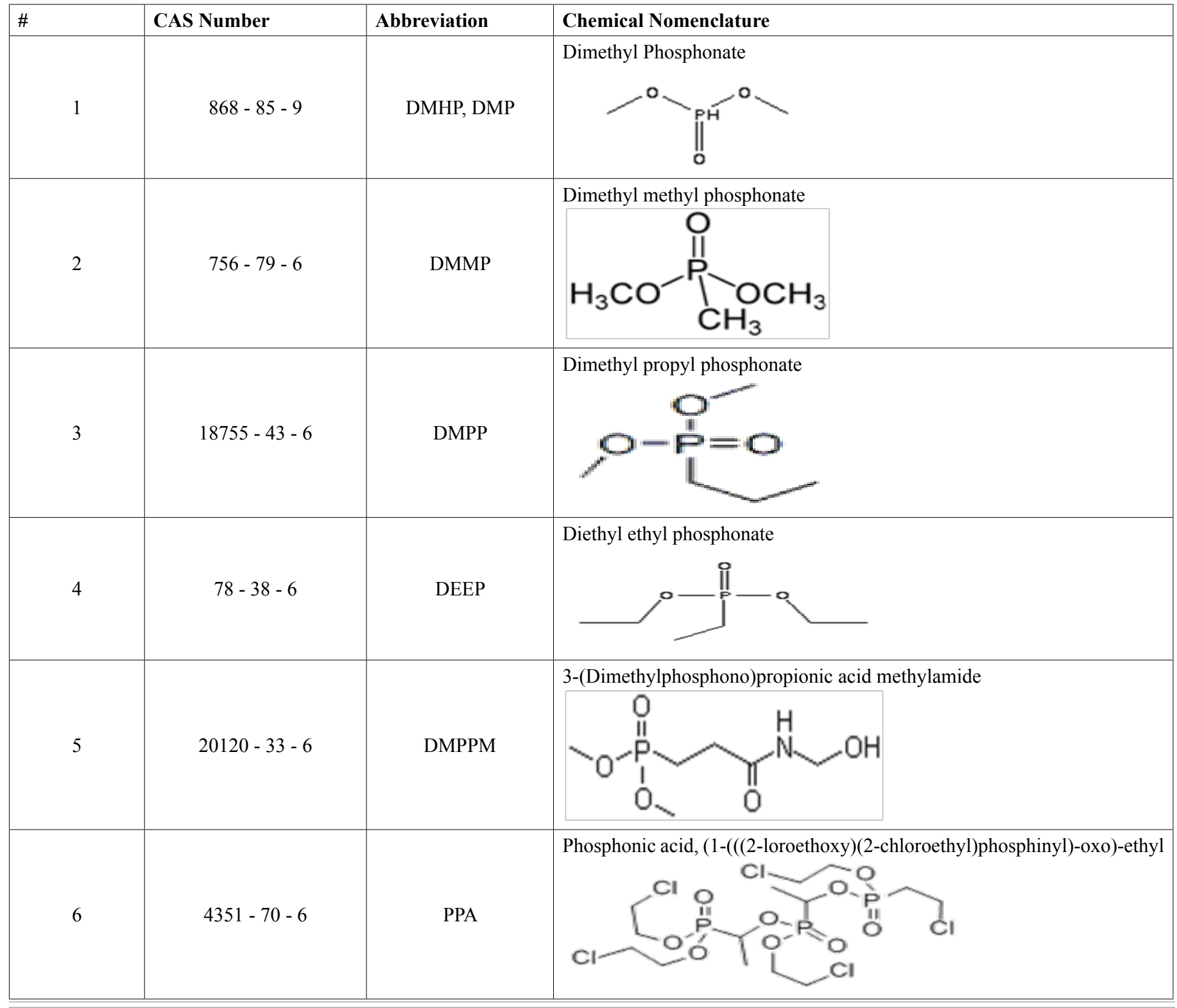




\section{Organophosphintes}

e.g., Hydroxymethylphenyl phosphinic acid, Phenyl Phosphinic acid, p-Methoxyphenyl Phosphinic acid, Carboxyethyl-phenylphosphinic acid and Diethyl phosphin

Table 8: Organophosphinite Flame Retardants

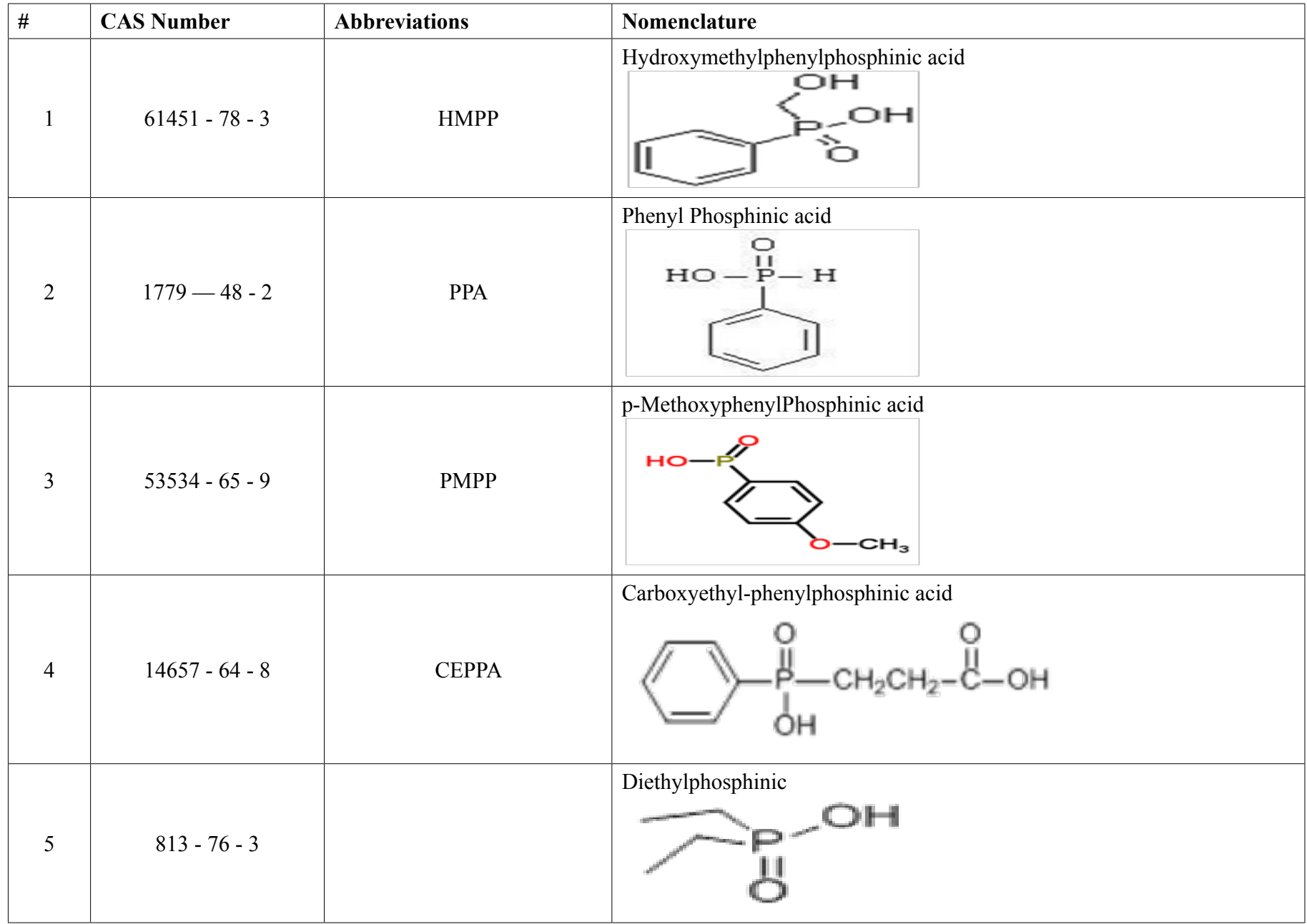

\section{Organophosphine oxides}

e.g., Tris(hydroxymethyl) phosphineoxide Bis(4-carboxyphenyl) phenylphosphine oxide Triphenyl phosphineoxide

Table 9: Organophosphineoxide Flame Retardants

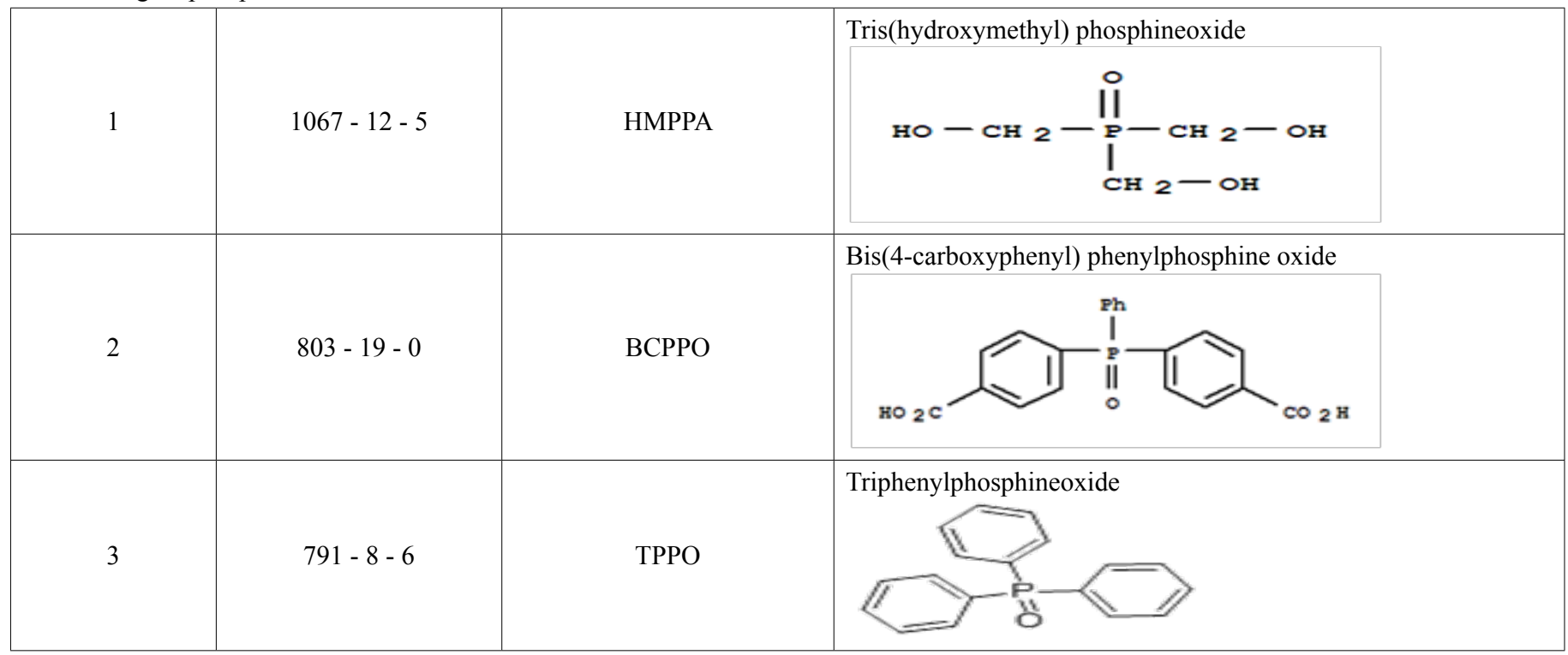




\section{Organohosphites}

e.g., triisopropyl Phosphite and tri-phenyl Phosphite.

Table 10: Organophosphite Compounds Flame Retardants

\begin{tabular}{|c|c|c|c|c|}
\hline$\#$ & CAS \# & Abbreviation & Chemical Nomenclature & Chemical Formula \\
\hline \multirow{2}{*}{1} & $116-17-6$ & $\mathrm{TIPPi}$ & Triisopropyl Phosphite \\
\hline & $101-02-0$ & $\mathrm{TPPi}$ & Tri-phenyl Phosphite
\end{tabular}

Triphenyl phosphite (TPPi): TPPi is used as a flame retardant to enhance the thermal stability of the electrolyte (Jia et al, 2014). Furthermore, TPPi improved the safety of chargeable lithium batteries with sulfur (Li-S) composite electrode and enhanced the electro-performance of the Li-S batteries.

\section{Neurotoxicity of OPFRs}

Organophosphorus compounds have three neurotoxic actions: cholinergic neurotoxicity (Abou-Donia, 2003), organophosphate-induced del compounds ayed neurotoxicity (OPIDN, Abou-Donia, 1981. Abou-Donia and Lapadula, 1990), and organophosphate-induced chronic neurotoxicity (OPICN, Abou-Donia 2003). The last action includes organophosphates-induced endocrine disruption.

\section{Cholinergic Neurotoxicity}

The primary action of organophosphates is irreversible inhibition of acetylcholinesterase (AChE), resulting in the accumulation of acetylcholine and subsequent over stimulation of the nicotinic and muscarinic acetylcholine receptors leading to cholinergic effects (Abou-Donia, 2003). Acute exposures to an organophosphate are potentially fatal. Sub-acute levels are not necessarily fatal and may not even rise to the level of producing any initial observable or measurable symptoms in the exposed individual. Acute exposure to organophosphates at toxic dose levels in mammals causes some or all of the symptoms of organophosphorus ester cholinergic toxicity which include: constriction of pupils, difficulty with involuntary muscles (e.g., gastrointestinal tract muscles resulting in involuntary defecation and urination), sweating, wetness of the mouth, excessive salivation, excessive clear mucus from the nose, tearing of the eyes, fluid in the lungs, shortness of breath, slowing of the heart, tremors of the voluntary muscles (e.g., those muscles used to perform ordinary tasks such as picking up an object), nausea and vomiting, impaired gait and fatigue.

In assessing the long-term adverse health effects of OPFRs, it very important to differentiate between toxicity induced following acute, high-level exposure and that after sub-acute, low-level exposure. Although the oral acute toxicity of a chemical, as indicated by the $\mathrm{LD}_{50}$ is high, it does not follow that this particular chemical is safe after long-term, low-level, sub-acute exposures. For example, cigarette smoke is not acutely toxic, and does not cause immediate death for those who smoke. On the other hand, available human incidents and experimental results indicate that long-term effects of cigarette smoking cause lung cancer and kill thousands of smokers every year.

Clinical Manifestations resulting from cholinergic toxicity: Organophosphate-induced cholinergic neurotoxicity may be caused by small level resulting in the following symptoms: Flu-like effects, fatigue, headache, inability to concentrate, weakness, dizziness, tremors, sweating, and anxiety (Abou-Donia, 1994, 1995).

Mild toxicity: Fatigue, dizziness, sweating, anorexia, headache, and malaise, tongue and eyelids tremors, miosis, visual impairment, and chest tightness (increased secretions and bronchospasm).

Moderate toxicity: Symptoms of the mild toxicity plus increased secretions in the form of salivation and lacrimation; involvement of the cardiovascular system: decreased pulse, bradycardia, and fall of blood pressure.

Severe toxicity: Increased the intensity of all the mentioned manifestations; chest tightness may reach respiratory failure leading to asphyxia because of the bronchospasm and laryngospasm in addition to increased secretions; cardiovascular manifestations: tachycardia and arrhythmia may develop up to heart block; advanced stage: convulsions and coma and may lead to death. 


\section{Cholinergic Toxicity Induced by OPFRs}

Human exposure to OPFRs results in cholinergic neurotoxicity in a dose-dependent manner. As an example of the cholinergic toxicity induced by tri-ortho-cresyl phosphate (TOCP), an incident of poisoning of 58 cases was reported in Bombay, India in 1960 (Vora et al. 1962). The manifestations of those cases were similar to the typical picture of cholinergic toxicity stated above consistent with the inhibition of erythrocyte acetyl cholinesterase was reduced by $50 \%$ within a short time of the onset of clinical symptoms and it recovered in 3 months. Also, it was reported that workers exposed to triphenyl phosphate (TBP) were presented with nausea and headache (ACGIH, 2001).

Oral administration of large doses of TOCP to chickens produced acute cholinergic effect including leg weakness, diarrhea, and salivation (Carrington et al. 1988, Carrington and Abou-Donia, 1988a). Also, administering of large doses of TBEB to Wiser rats caused irregularity in respiration, mainly depressed respiratory rate, with increased salivation and tremors (Hoechst 1989 cited in IPCS 2000).

\section{Organophosphate-Induced Delayed Neurotoxicity (OPIDN)}

OPIDN is a neurodegenerative disorder characterized by central-peripheral axonopathy and the presence of a latent period (usually ranges between 6 and 14 days from the exposure) or a delayed onset of neurological manifestations, mainly locomotors ataxia followed by paralysis after a single or repeated exposure to organophosphorus esters (Abou-Donia 1981, Abou-Donia \& Lapadula 1990).

The earliest cases of OPIDN resulted from consuming of tri-o-cresyl phosphate (TOCP)-containing creosote oil as a treatment for pulmonary tuberculosis in the nineteenth century, mainly in 1899 in France. Then in the early 1930s, tens of thousands of patients in the US developed paralysis, known as "Ginger-Jake" paralysis, after consumption of a TOCP- adulterated ginger extract called "Jamica Ginger" (Smith et al., 1930; Aring 1942). Since then, incidence of OPIDN in Europe, Africa and all over the world was recorded (Abou-Donia and Lapadula 1990).

Developing OPIDN depend on: a) the OP compound, b) dosage, c) frequency and duration of exposure, d) route of administration, e) metabolism, and toxicokinetics (which depends on the species-selectivity of the OP compounds). The compounds causing OPIDN have the some common features: a) they are OP compounds, b) they are direct or indirect inhibitors of esterases, c) presence of a latent period between exposure and appearance of clinical manifestations, d) they affect central (excluding higher brain) and peripheral nervous systems, e) producing well-defined neuropathological lesions related to the clinical neurological manifestations, and f) species-selectivity character (Abou-Donia, 1980; Abou-Donia \& Lapadula 1990).OPIDN characteristics are categorized into three main categories: biochemical, histopathological, and molecular alterations.

Biochemical changes: Early studies (Aldridge 1954) excluded both acetylcholine esterase AChE (Bloch and Hottinger 1943) and BChE (Earl \& Thompson 1952 a,b) as primary targets of delayed neurotoxicity (Aldridge \& Barnes 1966). Later, an enzymatic activity that was inhibited by OPs capable of producing OPIDN and was named Neurotoxicity Target Esterase (NTE) was proposed as the putative target for OPIDN (NTE) (Johnson 1969). This theory has not proven to be true and further evidence demonstrated that NTE-knockout mice show sensitivity to OPIDN, confirming that NTE isn't involved in the mechanism of the delayed toxicity (O’Callaghan et al., 2003).

Histopathological changes: OPIDN is characterized by primary axonal degeneration followed by secondary demyelination of specific regions in the central and peripheral nervous systems.

\section{Central Nervous System}

The site of degenerations of the myelin and axons is the spinocerebellar tracts and the posterior columns and cortico spinal tracts which degenerate below the cervical levels far away from their cell bodies (Abou-Donia 1981). The degenerative hallmarks include neurofilaments, vesicular and mitochondrial degeneration, aggregation and disintegration (Cavanagh 1964, Prineas 1969, Illis 1966). However, the higher centers aren't affected (Abou-Donia et al. 1981).

\section{Peripheral Nerves (Motor \& Sensory)}

TOMPP-treated cats and chickens demonstrated alterations in the axoplasm including accumulation of neurofilaments and neurotubules without affecting mitochondria in the early stages of developing ataxia. Also, those cats showed damage to the sensory system in both the interosseous and flexor digitorum brevis muscles of the foot (Cavanagh 1964, Prineas 1969, LeVay et al. 1971). Electron microscopic studies showed granules and degeneration of mitochondria and synaptic vesicles without affecting pre- and postsynaptic membranes (Prineas 1969). Regarding the effect on muscles, it was shown that victims of "Ginger-Jake" paralysis showed loss of muscle fibers and replacing those fibers with connective fat and tissue due to poisoning with TOCP (Aring, 1942).

\section{Mechanisms of OPIDN}

Protein kinases have been hypothesized as targets of OPIDN (Patton et al, 1983; Abou-Donia et al., 1984), based on three observations: a) organophosphorus compounds are phosphorylating agents, so they will interfere with the normal kinase-dependent phosphorylation of target proteins; b) early histopathological events in OPIDN are changes in the cytoskeletal structure (including microtubules and neurofilaments; c) the structure and function of cytoskeletal proteins are dependent on kinases-mediated phosphorylation. Follow-up studies established calcium/calmodulin kinase II as the major target for OPIDN. Thus, it was found that 
di-isopropyl phosphorofluoridate (DFP)-treated hens caused increase in the autophosphorylation and hence the enzymatic activity of CaM kinase II, in addition to amplification of its expression on both of the protein and mRNA levels (Schulman 1988, Patton et al. 11983, 986, Suwita et al. 1986, Abou-Donia 1993, Gupta and Abou-Donia 1998). As a result, the phosphorylation of cytoskeletal proteins as: tubulin and tau proteins were increased (Gupta and Abou-Donia 1994, Gupta \& Abou-Donia 1998). Microtubules (MTs) are formed of polymers of alpha- and beta- tubulin proteins (Janke and Kneussel 2010). One of the main functions of microtubules in neurons is preserving the stability and participating in producing neuronal plasticity via organization of intracellular compartments and trafficking of the cargo molecules to the pre- and postsynaptic domains (Lim et al. 2014, Janke and Kneussel 2010). As a member of the microtubule-associated proteins (MAPs) family, tau protein is found mainly in the neural tissue in addition to being found in trace amounts in non-neuronal cells (Weingarten et al. 1975, Buee et al. 2000). Binding of tau proteins to microtubules through binding domain give the microtubules the chance to be connected to both cytoskeletal structures (as neurofilaments) and other organelles (as mitochondria) as well (Leterrier et al. 1982, Miyata et al. 1986, Rendon et al. 1990, Buee et. 2000). Furthermore, phosphorylation state of tau protein is a regulatory key of microtubule assembly (Biernat et al. 1993, Clevland et al. 1977 a, b). The homeostasis of tau protein in the neurons is controlled by a balance between phosphorylation and dephosphorylation. Although the phosphorylated tau is more effective than the dephosphorylated state in the process of microtubule assembly or polymerization, it was demonstrated that the hyper-phosphorylation (increased phosphorylation) disrupts tau's homeostasis and hence the association between the microtubule and tau (Lindwall and Cole 1984, Lim et al. 2014). Moreover, it was found that neuron degenerations (neurodegenerative diseases) are associated with hyper-phosphorylation and aggregation of tau protein (Reddy 2011, Brunden et al. 2008, Iqbal et al. 2009, Timm et al. 2008). In OPIDN, there is marked inhibition of fast axoplasmic flow (Pleasure et al. 1969, James \& Austin 1970, Reichert \& Abou-Donia 1980, Gupta et al., 2001). This leads to the assumption that tau protein is one of the leading causes of neurodegeneration through its association with microtubules; and hence affecting the stability of neurons. We postulate that protein CaMkinaseII can be the main target of OPIDN leading to necrosis and apoptotic cell death.

\section{Clinical manifestation of OPIDN}

OPIDN has four distinct clinical phases: 1). Delayed phase before onset of clinical signs of one to four weeks with an average of 2 weeks (Abou-Donia and Lapadula 1990), 2) Progressive Phase (3 - 6 months); exhibiting early symptoms of peripheral neuropathy as: cramping, burning and pain in the calves of the legs. Concurrently or within a short time after that tingling and numbness sensation in feet and legs start. "Glove and Stock" hypothesia is the first characteristic sensory manifestation to take place (mainly in feet). These symptoms are followed by decreased sensation of touch, pain, temperature in the same manner of hypothesia. 3) Stationary phase (3 - 12 months) characterized by two properties; persistence of paralysis which may be paraplegia or quadriplegia, and disappearance of sensory manifestations within 2-9 weeks after the progressive stage. 4) Improvement phase that takes place 6-18 months after the onset of manifestations. Recovery takes place in a reversed manner when compared to incidence of the lesion, where hands recover first then feet and legs. Furthermore, the extensors recover first.

Progress and prognosis: It depends on the severity of the lesion in the peripheral nervous system; and whether the CNS is affected. If CNS is affected, the characteristic picture of the upper motor neuron lesion will take place with no recovery and with no significance attributed to the severity of the lesion in contrast with what happens in case of peripheral nervous system affection.

\section{Organophosphate-Induced Chronic Neurotoxicity (OPICN)}

The third neurotoxic action induced by organophosphates is a long-term neurological and neurobehavioral deficits accompanied by brain neuronal cell death that has been characterized recently as organophosphorus ester-induced chronic neurotoxicity (OPICN; Abou-Donia., 2003). This action can occur following a single acute organophosphate exposure at a toxic dose level or to small sub-acute exposures at sub-lethal dose levels, and results in long-term cognitive deficits and sensorimotor dysfunctions, even in the absence of clinical signs of acute cholinergic toxicity. Individuals with OPICN develop a chronic neurotoxicity that persists for years after exposure and is distinct from both the acute cholinergic action and OPIDN actions. OPICN is a nervous system disorder induced by organophosphorus compounds which involves neuronal degeneration and subsequent structural, functional, physiological, and neurological and neurobehavioral abnormalities and neuropsychological consequences and is largely characterized by chronic neurobehavioral alterations. Within the brain, neuropathological lesions are seen in various regions which are characterized by neuronal cell death, resulting from early necrosis or delayed apoptosis and may be diagnosed as central and/or cerebral atrophy of the brain. The regions of the brain that exhibit neuronal degeneration include the hippocampus, resulting in cognition and memory deficits as well as problems with emotions. Such effects may result from exposure to high doses that cause acute cholinergic neurotoxicity, as well as by low-level, sub-clinical doses of organophosphorus compounds.

OPIDN results from death of brain cells in various regions in the brain such as the cerebral cortex, hippocampus and cerebellum. Damage to these areas results in the following neurological deficits:

Cortex damage: results in dysfunctions in fine motor control movements, e.g., fingers, speech (laryngeal muscles), it also leads to muscle weakness and getting tired easily.

Hippocampus damage: causes cognition and memory deficits as well as emotional problems

Cerebellum damage: results in change in gate (ataxia) and body imbalance, disorders in the coordination of hand and finger muscle, 
and body tremors.

\section{Neurotoxicity of Specific Organophosphorus Flame Retardants Aliphatic Organophosphates Flame Retardants}

Tributyl Phosphate (TBP): The oral $\mathrm{LD}_{50}$ tributyl phosphate (TBP) in rats and chickens is 400 and $1,500 \mathrm{mg} / \mathrm{kg}, \mathrm{respec}-$ tively (ACGIH, 1986). The $\mathrm{LC}_{50}$ in rats is $1,359 \mathrm{mg} / \mathrm{m}^{3}(125 \mathrm{ppm})$. Despite showing the signs of cholinergic toxicity using an $\mathrm{LD}_{50}$ dose, test animals didn’t show any clinical sign of OPIDN (Carrington et al. 1989, 1996; Healy et al. 1995; Johannsen et al. 1977). Also, TPP does not produce OPIDN in hens (Johannsen et al. 1977). Its potential to produce OPIDN following exposure to multiple small doses has not been reported. It is significant that although TBP is a weak acetylcholine inhibitor in rats, inhalation exposure to $15 \mathrm{mg} / \mathrm{m}^{3}$ TBP caused workers to complain of nausea and headache (ACGIH, 1986). Development of acute cholinergic neurotoxicity symptoms in humans exposed to TBP, indicate that it is readily absorbed primarily via inhalation, leading to its accumulation in the nervous system and resulting in acute poisoning. The Threshold Limit Value (TLV) for TBP is $2.2 \mathrm{mg} / \mathrm{m}^{3}(0.2 \mathrm{ppm})$ and its Permissible Exposure Level (PEL) is $5 \mathrm{mg} / \mathrm{m}^{3}$ (ACGIH, 1986).

Tributoxyethyl phosphate (TBEP): In an 18-week study, Sprague Dawley male and female rats were treated with TBEP in two doses either 0.25 or $0.5 \mathrm{ml} / \mathrm{kg}$ bw for 5 days/week (Laham et al. 1984). Treated female rats showed ataxia and muscular weakness which disappeared 4 weeks later. Ataxia was confirmed by significant reduction of nerve conduction velocity at the end of the 18 weeks. This was consistent with histopathological, degeneration of the sciatic nerve was spotted by light and electron microscope examination. TBEP caused chronic neurotoxicity (OPICN) in male and female Sprague Dawley rats in a dose-dependent manner, where the high doses result in advanced degeneration. Degenerative lesion was supported by electrophysiological tests; where, they reported reduction in caudal nerve conduction velocity, in addition to the histopathological degenerative findings, consistent with OPICN (Laham et al. 1984, a and b;1985).

Tris(2-ethylhexyl) phosphate (TEHP): No studies were reported regarding OPIDN of TEHP. This compound was studied in guinea pigs following 6 hours aerosol exposure daily for 5 daily for 5 days/week for 3 months. Neither the biochemical investigations (plasma and erythrocyte cholinesterase activity) nor the histopathological studies of the sciatic nerve and the spinal cord were affected.

\section{Bromo Aliphatic organophoshate Flame Retardants \\ Tris(2,3-dibromopropyl) phosphate (TDBP): No enough information about its neurotoxicity is available.}

\section{Chloro Aliphatic Organophosphates Flame Retardants}

Tris(1,3-dichloroisopropyl) phosphate (TDCPP): TDCPP is a poor inhibitor of acetylcholinesterase, and has low acute toxicity (Meeker et al., 2013). Animals that were treated with very high doses ( $>1 \mathrm{~g} / \mathrm{kg} /$ day) exhibited clinical signs of organophosphate poisoning, including muscle weakness, loss of coordination, hyperactivity, and death (Carignan et al., 2013).

No studies have been reported for the ability of TDCPP to produce OPIDN. However, there are several in vivo and in vitro studies reporting its neurotoxicity (Kamata et al. 1989, IPCS 1998, Bullock \& Kamienski 1972, Dishaw et al. 2011).

Mice treated with a single oral dose of TDCPP-treated exhibited ataxia in addition to convulsions and hyperactivity 14 days after treatment. (IPCS 1998, Kamata et al. 1989). On the other hand, TDCPP-treated hens didn't exhibit signs of OPIDN (Bullock \& Kamienski 1972 cited in IPCS 1998). In this study, TDCPP was given orally to white Leghorn hens in a dose of $420 \mathrm{mg} / \mathrm{kg}$ bw for 5 consecutive days and then observed for 21 days; however, no clinical signs of delayed neurotoxicity were detected. In another study (Wang et al. 2015), Zebrafish embryos were given TDCPP for six months until sexual maturation. The five days post fertilization larvae didn't show any biochemical or molecular changes in the expression of proteins related to CNS development as alpha-tubulin. However, downregulation of nervous system developmental genes was reported in adult fish. On the other hand, the result that alpha tubulin protein expression was affected, suggests that polymerization of microtubules may be affected leading to neurotoxicity. Furthermore, Wang et al. postulated that accumulation of TDCPP in brain tissue may be a possible mechanism for TDCPP neurotoxicity by directly targeting the brain.

It was demonstrated that TDCPP causes neurotoxicity in vitro using PC12 cells (Dishaw et al. 2011, Ta et al. 2014). Dishaw et al. reported that TDCPP showed concentration-dependent neurotoxicity in PC12 cells (Dishaw et al. 2011,) Furthermore, treating PC12 cells with TDCPP resulted in different actions on expression of some genes; where, it caused the decrease in expression of GAP43, Nf-H and tubulin proteins as well (TA et al., 2011). On the other hand, it led to the increase of the expression of CaM KII gene. These effects explain TDCPP-induced neurotoxicity via affecting neural network structures, growth of neural synapses, damaging nerve fibers and hence preventing information exchange between neurons (Wang et al., 2015)..

Tris(2-chloroethyl) phosphate (TCEP): Despite being widely used as a flame retardant, not many studies have been done to evaluate its ability to induce OPIDN. The neurotoxicity of TCEP has been reported more than once (Tilson et al. 1990, Umezu et al. 1998, Ta et al. 2014). A case of 5-year old girl exposed to TCEP in household timber ( $600 \mathrm{mg} / \mathrm{kg}$ wood) was reported to develop neurological deficit. The girl was exhibited symptoms characteristic of OPIDN such as weakness in the arms and abdominal muscles, in addition to reduction of nerve conduction velocity. Furthermore, 9 months later she was admitted to hospital with dystelectatic pneumonia; where the final diagnosis was spinal muscle atrophy with no further functional abnormalities detected at 2 years post exposure (NICNAS report No. 17, 2001) 
TDCPP was evaluated for OPIDN using white Leghorn hens in comparison with TOCP-treated hens as positive control (Bullock \& Kamienski, 1972). No signs of OPIDN were shown in case of TCEP in contrast with TOCP-treated hens. In another study on White Leghorn hens, Sprague et al. 1981 evaluated the neurotoxicity of TCEP. The animals were given two doses of TCEP 3 weeks apart. In the group which survived, the histopathological examination of the brain, spinal cord and sciatic nerve showed no abnormality. Furthermore, biochemical evaluation of a separate group of hens (assessing NTE and plasma cholinesterase) was done after 24 hours of the first dose; where inhibition in cholinesterase activity was reported. However, no OPIDN was demonstrated (Sprague et al. 1981).

In the same study on PC12 cells, Ta et al. showed that treating PC12 cells with TCEP lead to similar results to that of TDCPP. Moreover, TCEP led to decrease in the protein level of GAP43, and the tubulins; while it resulted in increasing in that of CaM KII and NF-H proteins. The same as TDCPP, affecting those proteins' expression on the gene and protein level led to neurotoxicity via the effect mentioned earlier (Ta et al. 2014).

\section{Aromatic Aliphatic Organophosphates Flame Retardants}

Dibutyl Phenyl Phosphate (DBPP): The oral $\mathrm{LD}_{50}$ of dibutyl phenyl phosphate (DBPP) in rats is $2,140 \mathrm{mg} / \mathrm{kg}$. Its TLV is $3.5 \mathrm{mg} /$ $\mathrm{m}^{3}(0.3 \mathrm{ppm})$ (ACGIH, 1986). In humans, DBPP causes eye injury and is an irritant to the skin and upper respiratory tract (ACGIH, 1986). Aerosolized or vaporized DBPP produced nose and throat irritation accompanied by coughing and wheezing. DBPP did not pr OPIDN in hens following oral administration (Hathaway 2004).

Butyl Diphenyl Phosphate (BDPP): No information is available on the toxicity of BDPP.

2,6-Di-tert-butyl-p-cresol (butylated hydroxytolune, BHT): The oral $\mathrm{LD}_{50}$ of BHT in rats is greater than $2,930 \mathrm{mg} / \mathrm{kg}$. It functions as an antioxidant. BHT has a TLV of $2 \mathrm{mg} / \mathrm{m}^{3}\left(0.22 \mathrm{ppm}\right.$ ) and a PEL of $10 \mathrm{mg} / \mathrm{m}^{3}$ (ACGIH, 1986). Ingestion of 4 and $80 \mathrm{~g}$ of BHT by two patients resulted in transient dizziness, brief loss of consciousness, unsteadiness of gait and slurred speech.

\section{Aromatic Organophosphates Flame Retardants}

Triphenyl Phosphate (TPP): No delayed neurotoxicity in TPP-treated hens (Johannesen et al. 1977). Nine hens were treated by $5000 \mathrm{mg} \mathrm{TPP} / \mathrm{Kg} \mathrm{bw}$, and then observed daily till sacrificed on the $42^{\text {nd }}$ day of experiment. However, no pathological findings of OPIDN were observed. In accordance with Johannesen's study, Wills et al. demonstrated that TPP-treated cats didn't show OPIDN clinically or histologically (Wills, et al. 1979).

Also, in vitro studies were done to evaluate TPP's ability to induce neurotoxicity. It was reported more than once that TPP can cause neurotoxicity (Gant et al. 1987, Flaskos et al. 1994, Hendricks et al. 2012). However, Hendricks et al. reported in 2014 that TPP doesn't induce neurotoxicity in Phenochromocytoma (PC12) cells or neuroblastoma (B35) cells (Hendricks et al. 2014).

In a study evaluating workers in a TPP-producing plant, Sutton et al (1960) reported that the only difference between exposed and non-exposed groups was in the red blood cell cholinesterase activity (Sutton et al. 1960). They reported $18 \%$ decrease in cholinesterase activity in the exposed group with no clinical manifestations, or unusual lab findings when compared to the non-exposed group. As a result, it was concluded that TPP doesn't induce neurotoxicity.

TCP or trimethyl phenyl phosphate (TMPP) is composed of several ortho $(o)$, meta $(m)$, and para $(p)$ isomers at the following ratios: $15-25 \%$ tri-meta-cresyl phosphate, $5-10 \%$ tri-para-cresyl phosphate, $60-75 \%$ mixed meta- and para-cresyl phosphate, and small amounts of ortho-cresyl phosphates (mainly in the mono-ortho-cresyl form), with low amounts of di-ortho-cresyl isomers and minute amounts of the tri-ortho-cresyl isomer, resulting in more than 10 cresyl isomers. Because jet oils contain up to 3\% TCP as an anti-wear agent, inhalation exposure to the chemical constituents in this product is likely. Although the cholinergic neurotoxicity of TCP isomers is low, six members of this group of chemicals contain one or more of the ortho-cresyl moiety and are capable of causing OPIDN.

There are 10 possible TCP isomers (Ramsden, 2013) listed in Table I.

Table I: Isomers tri-cresyl phosphate (TCP)

\begin{tabular}{|l|c|c|}
\hline Ortho Content & Isomers & OPIDN \\
\hline Tri-ortho-MPP (TOMPP) & $o, o, o$ & + \\
\hline Di-ortho-MPP (DOMPP) & $o, o, m, o, o, p$ & + \\
\hline Mono-ortho-MPP (MOMPP) & $o, m, m$ o, $m, p$ o,p,p & + \\
\hline Non-ortho-TMPP & $m, m, m m, m, p \quad m, p, p \quad p, p, p$ & - \\
\hline
\end{tabular}

+ , Produces OPIDN

_, does not produce OPIDN

The oral $\mathrm{LD}_{50}$ of TOMPP in rats and chickens is more than 4,640 and $10,000 \mathrm{mg} / \mathrm{kg}$, respectively (ACGIH, 2001). In contrast, a single oral dose of $250 \mathrm{mg} / \mathrm{kg}$ or 36 daily oral doses of $0.5 \mathrm{mg} / \mathrm{kg}$ (total dose of $18 \mathrm{mg} / \mathrm{kg}$ ) TOCP produces OPIDN in adult hen, the animal of choice to study OPIDN, indicating that daily small doses were seven times more effective than a single oral dose in producing OPIDN (Abou-Donia, 2005). Further more, the dose of TMPP needed to cause OPIDN is more than 4,000 times the 
dose required to elicit acute cholinergic toxicity.

Consistent with this is the finding that inhalation exposure to TMPP, in a manufacturing plant, produced toxic polyneuritis (Hunter et al., 1994). Furthermore, jet engine lubricating oils contain up to 3\% TCP- including $0.1 \%$ TOCP, the potent OPIDN-producing isomer (Hewstone, 1994). Also, long-term inhalation exposure of chickens to concentrations of between 23 and $100 \mathrm{mg} /$ m3 produced neurotoxic effects (Barrett and Oehme, 1985). It has been suggested that humans are 10 to 100 times as susceptible to developing OPIDN as chickens, the animal required by the U.S. EPA to test organophosphates for OPIDN (Barrett and Oehme, 1985The available information suggests that the inhalation of contaminated aircraft cabin air may be related to OPICN. Aircrew members (including pilots and flight attendants) have consistently complained of neurological illnesses, such as headache, dizziness, cognitive dysfunction, difficulty concentrating, tremors, generalized weakness and lack of motor control, which are typical of OPICN. A study reported an unexpected high neurotoxic potency of aviation engine lubricants containing 3\% TMPP levels and less than $0.02 \%$ of ortho-isomer (Freudenthal et al., 1993).

In addition to the ortho-isomer, the presence of para-methyl phenyl phosphate (TPMPP) has been confirmed in two jet engine lubricating oils, Castrol 5000 and Exxon 2380 (Van Netten, and Leung 2000). Furthermore, preliminary results have shown that dermal exposure to each of the three isomers (that is, TOMPP, TMMPP, and TPMPP) caused sensorimotor deficits in rats and neuropathological lesions in the brain. Although most of the investigations of the health effects caused by contaminated cabin air have focused on OPIDN, TMPP and its constituent isomers, other components of the hydraulic fluids and engine lubricating oils should also be studied for their action in producing OPICN. These chemicals include: tributyl phosphate; tri-isobutyl phosphate; butyl diphenyl phosphate; dibutyl phenyl phosphateand tri-phenyl phosphate.

\section{Endocrine Disruption by OPER}

Organophosphorus Compounds are endocrine disruptors that interfere with the natural hormones of the body. The endocrine system is composed of glands of an organism that secrete hormones directly into the circulatory system which are carried to a distant target organ. The major endocrine glands include: pineal gland, pituitary gland (O'Connor et al., 2000), Pancreas, Ovaries, testes, thyroid gland (Dickhoff et al, 1983), parathyroid gland, gastrointestinal tract (Pederson et al., 2008), adrenal glands and hypo-thalamus (Silverman et al., 2005). In vertebrates, the hypothalamus is the neural control center for all endocrine systems. In contrast, the exocrine system, which secretes its hormones using ducts. The endocrine system's effects are slow to initiate, and prolonged in their response, lasting from a few hours up to weeks. Endocrine disruptors cause endocrine diseases that are characterized by disregulated hormone releases of the endocrine system

\section{Developmental Toxicity}

Infants and young children are believed to have a higher exposure to FRs when compared with adults because they spend more time indoors, in close proximity to contaminant sources, and engage in frequent hand-to-mouth contact (US EPA, 2008). A recent study found that toddlers had significantly higher exposure levels to TDCPP compared with their mothers (Butt et al., 2014). The higher levels in toddlers suggest that future research may be warranted to determine if exposure during early development is associated with adverse health outcomes in children.

Studies in animals showed that prenatal exposure to low levels of OPs (e.g., chlorpyrifos) produced behavioral changes in adulthood affecting memory and learning (Eaton et al., 2008). These developmental neurotoxic effects may be related to OPs impact on different neurotransmitter systems (e.g. elevation of acetyl choline in nicotinic and muscarinic receptors (Abou-Donia, 1995). Neurotransmitters affects development of nervous system in different ways, including regulating cell migration, replication, growth, and differentiation (Behra et al., 2004; Lauder and Schambra, 1999). Moreover, OPs pesticides have epigenetic effects which regulate neurotrophic factors during development of CNS (Slotkin et al., 2008).

In accordance with these postulations, the neurotoxicity of tris (1,3-dichloro-2-propyl) phosphate (TDCPP) comparing it to chlorpyrifos (CPF) was evaluated using PC12 cells system and different endpoints, e.g., changes in DNA synthesis, differentiation into different neurophenotypes, and neurite growth. TDCPP inhibited DNA synthesis, decreased cell number, and altered neuro differentiation (Dishaw et al., 2011) In this study, adverse effects in both the undifferentiated state and during neuro differentiation were observed. These findings indicate that developing nervous system is vulnerable to OPFRs effects from the earliest events of neural cell division till full differentiation. What was impressive in this work is that adverse effects of TDCPP were reported on using lower concentrations than CPF. Moreover, these results were not obtained through nonspecific cytotoxicity (as evidenced by absence of any effects on cell viability). It seems that the small degree of oxidative stress observed in the TDCPP studies may play a role in the observed outcomes. In PC12 cells, levels of oxidative stress that are insufficient to compromise cell viability are known to initiate neuro differentiation in the absence of NGF which was the landmark her for TDCPP induced effects (Katoh et al., 1997). In summary, profound effects on neural cell replication and neuro differentiation, processes that are critical to early neurodevelopment were observed (Dishaw et al., 2011).

In the same context but on another system, adult zebrafish, chlorpyrifos has shown neurobehavioral deficits in zebra fish (Eddins et al., 2010; Sledge et al., 2011). These behavioral changes were associated with altered neurotransmitter levels. Hence, OPFRs with similar chemical structure to chlorpyrifos e.g. TDCPP, TCPP, and TCEP, TDBPP were tested for their neuro developmental toxicity in zebra fish when compared to CPF (Dishaw et al. 2014). Those four agents were shown to readily pass through the chorion, accumulating in early life stage fish tissues. Thus, they suggested that early life OPFR exposure may result in developmental effects similar to CPF. Their work showed that these chemicals affect the developing nervous system at exposure levels that are not overtly toxic. TDCPP and TDBPP and their respective metabolites were detected in embryos on $5 \mathrm{dpf}$. For all chemicals tested, develop- 
mental exposures that were not overtly toxic significantly altered larval swimming activity, indicating that OPFRs adversely affect development of early life stage zebrafish. In this study, all chemicals induced behavioral effects in larvae at exposure levels that did not result in significant death or malformations that would affect swimming ability (e.g. stunted fin growth or spinal deformities). The authors suggested that altered swimming activity could be elicited by neurotoxicant effects of developmental OPFR exposure. Thus, OPFRs may have effects similar to organophosphate pesticides on neurotransmitter-mediated morphogenesis that are driving the behavioral changes observed in the present study (Dishaw et al., 2014).

Using the same assessment system, an investigation into the effects of acute and long-term exposure to TDCPP in zebrafish was carried out (Wang et al., 2015). Zebra fish embryos ( $2 \mathrm{~h}$ post-fertilization) were exposed to TDCPP (0-100 g/L) for 6 months up until sexual maturation. Concentrations of TDCPP and its metabolic product (bis(1,3-dichloro-2-propyl) phosphate, BDCPP) were measured in the tissues of 5 day post-fertilization (dpf) larvae. Although they noticed no effects on several endpoints e.g. locomotion, acetyl cholinesterase activity, levels of the neurotransmitters dopamine and serotonin, and expression of mRNAs in any exposure group, adult fish showed reductions of dopamine and serotonin levels in the brains of females but not males. These results may be more logic as they found that TDCPP concentrations were higher in female brains. In this work, they observed high body burdens of TDCPP in fish, indicating bioavailability and bioaccumulation of this hydrophobic chemical under laboratory exposure conditions ( $\log \mathrm{K}=3.76)(\mathrm{OEHHA}, 2011)$. They also observed the primary metabolite of TDCPP (BDCPP) that is produced in mammals (Cooper et al., 2011; Carignan et al., 2013). Moreover, high TDCPP (and BDCPP) contents were detected in brain tissue, suggesting that it is able to cross the blood brain barrier and accumulates in brain suggesting that the brain may be a key target organ for TDCPP toxicity and this may have direct effects on nerve cells, leading to neurotoxicity. Interestingly, chemical analysis showed lower ratio of TDCPP: BDCPP in larval stages, indicating that larvae may have high biotransformation potential. On the other hand, higher body burdens of TDCPP and BDCPP in larvae could also be due to larval fish having a lower capacity to excrete these chemicals. This is in accordance to a previous study with PBDE bioaccumulation in developing mice denoting that young animals have a reduced ability to excrete PBDEs during development (Staskal et al., 2006). These data may underline the potential hazardous effects of these structures in early developmental stages. 3.2.1 Mechanisms of OPFR-induced Developmental Toxicity

Organophosphphorus flame retardants disrupt normal development. TDCPP have been reported to affect embryonic survival, behavior (righting reflex) and Purkinje cell development in white leghorn chicken (Bradley et al., 2015). Exposure of chicken embryo to 45 ug/g TDCPP resulted in shorter head-to-bill lengths, decreased body weight, and smaller gallbladders, while 7.64 ug/g lowered free thyroxine (T4) levels in the blood (Farhat et al., 2013). Similarly, zebrafish raised in water containing TDCPP died or developed severe malformations. This can be explained by altering mRNA expression of several genes that regulate thyroid function in zebrafish embryos and larvae (Dishaw et al., 2011; Farahat et al., 2013). Early life exposure also changed thyroid hormone levels in both zebrafish and chick embryos: triiodothyronine (T3) levels increased in exposed zebrafish while thyroxine (T4) levels decreased in both species (Liu et al., 2012).

Another proposed mechanism for TDCPP developmental toxicity was also demonstrated by treating PC12 cells with TDCPP, where the cells showed decreased replication and growth, increased oxidative stress, and altered cellular differentiation (Farahat et al., 2013). In a developing organism, these effects could change the way the brain cells communicate and function, resulting in permanent changes in nervous system function (Mcgee et al., 2012). In another study, Na et al. (2014) investigated the effects of TDCPP and TCEP on the same cell system (PC12) with the same endpoints. In addition, they quantified mRNA and protein expression levels of CaMKII, GAP43, tubulin and NF-H. These two OPFRs led to decreased cell growth and increased apoptosis, moreover, there were significant changes in the gene and protein levels. TDCPP reduced levels of the six proteins plus GAP43, NF-H and the two tubulins, but it resulted in an increase in CaMKII gene levels. TCEP showed similar effects as of TDCPP beside an elevation in NF-H protein levels. In this study, the two major OPFRs, TDCPP and TCEP, were both shown to have the potential to elicit neurotoxicity. Furthermore, in their study, it was found that exposure to TDCPP or TCEP disrupts the developing nervous system, resulting in the loss of PC12 cells, an increase in cell apoptosis, damage to nerve fibres, a reduction of nerve nodes and the failed formation of neural network structures. Although both agents caused a concentration-dependent cytotoxicity and neurotoxicity, TCEP showed side effects at higher concentrations compared with TDCPP. They attributed these effects to the different halogen atoms which appear to be an important factor in determining the effects of OPFRs on phenotypic fate (Dishaw et al., 2011; Na et al., 2014)

In another system for assessing neurotoxicity, fertile domestic chicken eggs were injected with TCPP or TDCPP (maximum dose $=51,600$ and 45,000 ng/g egg, respectively) to determine effects on different parameters including development, and TH levels following 20-22 days of incubation. TDCPP exposure resulted in significant decreases in head length, and reduced plasma free T levels at $7640 \mathrm{ng} / \mathrm{g}$. Chemical analysis of egg contents at incubation days $0,5,11,18$, and 19 revealed that $>92 \%$ of the injected TCPP or TDCPP concentration was detectable up to day 5. The observed effects of TCPP and TDCPP exposure may be due to disruption of the TH hormone (Farhat et al., 2013, a,b).

\section{Reproductive Toxicity}

Men living in homes with high concentrations of TDCPP in house dust were more likely to have decreased sperm counts and increased serum prolactin levels (Freudenthal and Henrich 2000). Previous study has demonstrated $100 \mathrm{mg}$ TOCP/kg/day to be an OPIDN-inducing dose with minimal mortality in roosters. This dose level was administered to adult leghorn roosters (p.o., $\mathrm{n}=10$ ) for 18 consecutive days. By days 7-10 of the study, TOCP-treated birds exhibited limb paralysis characteristic of OPIDN. Analysis at termination revealed significant inhibition of neurotoxic esterase activity (NTE) in both brain and testis. There was also a slight decrease in brain acetyl cholinesterase (AChE) activity. Sperm motility was shown to be greatly decreased. In addition, 
sections of formalin-fixed, methacrylate-embedded testes from TOCP-treated birds showed vacuolation and disorganization in the seminiferous epithelium. The marginal body weight decreases (17\%) in treated animals were not considered to contribute to the testicular toxicity induced by TOCP. Parathion (O,O-diethyl-O-4-nitrophenyl phosphorothioate, $0.1 \mathrm{mg} / \mathrm{kg} / \mathrm{day}, \mathrm{p} . \mathrm{o} ., \mathrm{n}=3) \mathrm{was}$ used as a positive control for AChE inhibition and a negative control for inducing OPIDN. Roosters treated continuously with parathion showed a decrease in brain AChE activity, but no changes in NTE, testicular histology, or limb function. These studies demonstrate the testicular toxicity of TOCP in roosters and suggest that this effect is not related to the chemical's anticholinergic action (Somkuti et al., 1987b).

A subchronic 63-day study (reflecting the 49-day length of the rat seminiferous epithelium cycle plus the 14-day transit time of spermatids through the epididymis was initiated. Dose-dependent (10 to $100 \mathrm{mg}$ TOCP/kg/day) decreases in cauda epididymal sperm motility and density, testicular enzyme activities, and alterations in sperm morphology were observed. Concurrent pairfed controls (matched to the highest dose group, $100 \mathrm{mg}$ TOCP $/ \mathrm{kg} /$ day) indicated that weight loss resulting from TOCP administration had minimal contributory effects to the testicular toxicity seen. Plasma alpha-tocopherol acetate (vitamin E) and testosterone concentrations were unaffected. Tri- $p$-cresyl phosphate (TPCP), the non neurotoxic structural analog of TOCP, produced no toxic effects, demonstrating the necessity of the ortho-cresol moiety for induction of damage. A minimum effective (threshold) dose for observable testicular toxicity was determined to be $10-25 \mathrm{mg} \mathrm{TOCP} / \mathrm{kg}$ in this study. These data suggest that TOCP interferes with spermatogenic processes and sperm motility directly and not via an androgenic mechanism or decreased vitamin E availability (Somkuti et al., 1987a).

The onset and development of testicular lesions following tri-o-cresyl phosphate (TOCP) dosing have been documented through light and electron microscopic morphological studies. Male Fischer 344 rats $(190-210 \mathrm{~g}$ body weight $)$ were administered $150 \mathrm{mg} \mathrm{TOCP} / \mathrm{kg} /$ day in corn oil for $1,3,5,7,10,14$, and 21 days. Vehicle-treated rats served as the control group. Sections of formaldehyde- and glutaraldehyde-fixed, methacrylate-embedded testes showed, by Day 5, numerous spermatid heads apparently detached from tails lying at oblique angles near the basement membrane of the seminiferous tubules. Columnar and spherically shaped vacuoles of the epithelium, radiating from the basement membrane to the lumen of the tubules, were also observed. Electron micrographs revealed that these were localized in Sertoli cells. Widespread dilation of Sertoli cell smooth endoplasmic reticulum was also noted. By 7 days of treatment, residual body abnormalities were noted in stage VIII tubules, along with spermatocyte-derived multinucleated giant cells. The lesion progressed with increased vacuolation of the epithelium and numbers of abnormal residual bodies and giant cells, together with spermatid karyorrhexis (Days 10, 14, and 21). There was also an apparent decrease in sperm density/tubule with continued exposure: $90 \%$ of the seminiferous tubules were devoid of sperm by Day 14 . These morphological results indicate an initial effect of TOCP on Sertoli cells. Spermatogenesis is affected as seen by the decrease in sperm density and increase in necrotic spermatids (Somkuti et al., 1991)

\section{Hepatotoxicity}

In another study, exposing chicken embryonic hepatocytes (CEH) and chicken embryonic neuronal (CEN) cells to TDCPP and TCPP and using real-time reverse transcription-PCR (real-time RT-PCR) assays to test gene expression changes in genes associated with the chicken xenobiotic-sensing orphan nuclear receptor (CXR), the TH pathway, lipid regulation, and growth Crump et al. (2012) In this study, TDCPP was toxic to hepatocytes (LC5 60.3 $\pm 45.8 \mathrm{mM}$ ) and neuronal cells $\left(\mathrm{LC}_{50} 28.7 \pm 19.1 \mathrm{mM}\right)$, whereas TCPP did not affect viability in either cell type up to the highest concentration administered, $300 \mathrm{mM}$. However, both had a significant and similar impact on the expression of genes associated with CXR activation, the TH pathway, lipid regulation, and growth.

\section{Neurotransmitters}

Finally, the similarity in chemical structure may point to possible effects similar to organophosphate pesticides on neurotransmitter-mediated morphogenesis. OPFRs are derivatives of phosphoric acid with different substitutes including alkyl chains (e.g., tri-n-butyl phosphate (TnBP)), partly halogenated alkyl chains (e.g., tri(2-chloroethyl) phosphate (TCEP)) as well as aromatic contents (e.g., triphenyl phosphate (TPhP). Some studies showed that, similar to OPs pesticides, OPEs target esterases, such as the neuropathy target receptors. Animal data showed that some of these chemicals including tributoxyethyl phosphate (TBEP), TCEP, $\mathrm{TPhP}$ and tri- $m$-cresyl phosphate (TCrP) decreased AChE activity in rats (Bollman et al., 2012; Moller et al., 2012).

\section{Carcinogenicity}

Several studies showed that TDCPP is a carcinogenic. Rodents that were fed TDCPP over two years showed increased tumor formation in the liver and brain (Eaton et al., 2008). Metabolites of TDCPP were also determined to be mutagenic in bacteria using Ames test (Gold 1978). In 2011, TDCPP was listed as a carcinogen under California Proposition 65, a law that identifies and regulates chemicals determined by the California Environmental Protection Agency 'to cause cancer, birth defects or other reproductive harm (Eldefrawi et al., 1977).

The effects of the flame retardant tris(2,3-dibromopropyl) phosphate (Tris-BP) on growth, sister chromatid exchanges (SCE), and chromosome aberrations of Chinese hamster V79 cells cultured either in vitro or in diffusion chambers (DC) implanted into mice were studied. Tris-BP caused a dose- and time-dependent reduction of cell growth as measured by colony-forming activities (Furukawa et al., 1978). A significant dose-dependent increase in SCE was observed in V79 cells either in the cultures treated with Tris-BP or in DC in mice given injections of the chemical. In contrast, Tris-BP in V79 cells in culture, in V79 cells in DC in mice, in two human lymphoid cell lines, or in mouse bone marrow cells in vivo did not significantly increase chromosome aberrations. 
Tris(2,3-dibromopropyl) phosphate caused tumors in two rodent species, at several different tissue sites, and by two different routes of administration. Feeding of tris(2,3-dibromopropyl) phosphate caused benign or malignant tumors of the fore stomach (squamous-cell papilloma or carcinoma) and lung (bronchiolar/alveolar adenoma or carcinoma) in mice of both sexes; the kidney (tubular-cell adenoma or adenocarcinoma) in male mice and in rats of both sexes; and the liver (hepatocellular adenoma or carcinoma) in female mice. Dermal exposure to tris(2,3-dibromopropyl) phosphate caused tumors of the skin, forestomach, lung, and oral cavity in female mice. Because tris(2,3-dibromopropyl) phosphate was listed in the Second Annual Report on Carcinogens, an additional study in rodents has been identified. In a study of limited duration, administration of tris(2,3-dibromopropyl) phosphate by stomach tube caused benign colon tumors in male rats. There sufficient evidence that this compound to be a human carcinogen. (National Toxicology Program 2011).

\section{Other Actions}

Carboxylesterase (CBE): Some arylphosphates inhibited human monocyte carboxylesterase (CBE) activity (Saboori et al., 1991). Five arylphosphates including diphenyl phosphate, tribenzyl phosphate, tricyclohexyl phosphate, diphenyl methyl phosphate and $\mathrm{TPhP}$ inhibited human monocyte carboxylesterase (CBE) activity in an in vitro study, but the alkylphosphates (tributyl phosphate and triethyl phosphate) showed no similar effects (Saboori et al., 1991).

Lysine decarboxylase (LDC): Another target for OPEs neurotoxicity is lysine decarboxylase (LDC). LDC is one of the amino acid decarboxylases, which catalyze the conversion of amino acids (e.g. lysine, arginine, histidine, ornithine) into polyamines (e.g. cadaverine, agmatine, histamine, putrescine) (Kanjee et al., 2011).. Polyamines, are essential for optimal growth and viability (Tabor et al., 1982).

Recently, Wang et al. (2014) investigated the effects of 12 different OPFRs on (LDC) which is one of amino acid decarboxylases, using a fluorescence-based enzyme activity assay. These twelve OPEs variable inhibitory effects on LDC activity. Alkyl group substituted OPEs had no inhibitory effect. By contrast, six OPFRs substituted with aromatic or chlorinated alkyl groups inhibited LDC activity significantly with IC ranging from $1.32 \mathrm{mM}$ to $9.07 \mathrm{mM}$. These findings suggest LDC as a new potential biological target of OFRs (Wang et al., 2014).

GABA Receptors: Another example of neurotoxic OPFRs is TMPP; a bridged organophosphate that forms upon the partial pyrolysis of certain fire-retardant treated polyurethane foams or synthetic ester-based engine lubricants or hydraulic fluids (Wyman et al., 1993). It acts on $\mathrm{Cl}$ channel component of the GABA receptor ionophore complex and reduce GABAA modulated inhibition. Acute effects of TMPP in animals have been verified (Higgins and Gardier, 1990; Rossi et al., 1993, 1994, 1998). Moreover, TMPP caused down-regulation of trkB in response to TMPP which was attributed to the possible TMPP induced changes in neuronal functions with subsequent altered neurobehavioral capacity (Russel et al., 2002).

CaMKII and Cytoskeletal Proteins: A more recent study tested (neuro) toxicity of 13 HFFRs and three BFRs in dopaminergic pheochromocytoma (Pc12) and neuroblastoma (B35) cells by assessing similar endpoints. In this study, Hendricks et al. (2014) found a high neurotoxic potency for ATH, ZHS, ZS and MMT, a moderate neurotoxic potency for MPP, a low neurotoxic potency for BDe-209, TBBPA, RDP, TPP, DOPO, APP, ATO and MHO, and negligible neurotoxic potency for BPS, BDP and Alpi. (Hendricks et al. 2014). This neurotoxicity was due to different mechanisms; ATH, ZHS, ZS and montmorillonite (MMT) increased the basal intracellular calcium concentration ([ca 2+]), whereas tetrabromobisphenolA (TBBPA), resorcinol bis (diphenylphosphate) (RDP), TPP, 9,10-dihydro-9-oxa-10-phosphaphenanthrene-10-oxide (DOPO), ATH, ZHS, ZS and MMT reduced depolarization-evoked increases in $[\mathrm{ca} 2+]$ as a result of inhibition of voltage-gated calcium channels.

Environmental Exposure to OPFRs and Health: As for the OPFRs' health impact, concerns are growing. That is because the flame retardants do not chemically bond with the foam. They escape into the environment. When someone sits on a couch, air that bears chemical traces is expelled from the upholstery. Those substances settle on household dust, or drift outdoors, or find their way into rivers and even into mothers' breast milk. Small children, known to put almost anything in their mouths, are particularly vulnerable as they play on floors that have veils of chemically tainted dust. Now that society discovered the dangers of flame retardant chemicals in children's clothes more than 35 years after the use of these agents, it is hoped it doesn't take another 35 years to recognize the relationship between the placement in our kitchens of microwave ovens and the high incident of breast cancer.

Humans exposure to TDCPP and other flame retardants through several routes, including inhalation, ingestion, and skin contact with treated materials. Rodent studies show that TDCPP is readily absorbed through the skin and gastrointestinal tract (Marklund et al., 2005; Thorvald et al., 2004). Infants and young children are expected to have the highest exposure to TDCPP compared to adults, because children spend more time indoors and closer to the floor and they frequently put their hands and other objects into their mouths without washing. Several studies show that TDCPP can accumulate in human tissues. It has been detected in semen, fat, and breast milk (Regnery and Puttman 2010; Hudec et al, 1989; LeBel et al., 1989) and the metabolite bis (1,3-dichloropropyl) phosphate (BDCPP) has been detected in urine (Sundkvist et al., 2010).

Indoor: Usually, young children stay for long periods (ten hours per day, five days per week) in child care and preschool centers (Tulve et al., 2006). Early childhood education (ECE) facilities are located in a variety of building types, including homes, schools, commercial buildings, and portable classrooms. These facilities are of variable types including home-based child care providers, 
centers operated like private schools, and programs run by government agencies or religious institutions (Bradman et al., 2014). These circumstances lead to increased exposures levels of OPFRs to children.

A study of US house dust found that over $96 \%$ of samples collected between 2002 and 2007 contained TDCPP at an average concentration of over $1.8 \mathrm{ppm}$, while the highest was over $56 \mathrm{ppm}$ (Andersen et al., 2004). TDCPP was also detected in 99\% of dust samples collected in 2009 in the Boston area from offices, homes, and vehicles (Meeker and Stapleton 2010).

Home environment exposure to the two OPFRs, tris (1,3-dichloropropyl) phosphate (TDCIPP) and triphenyl phosphate (TPHP) were assessed and short-term variation in urinary metabolite concentrations ( $\mathrm{n}=11$ participants; $\mathrm{n}=49$ samples) were studied. The two OPFRs were detected frequently in hand wipes and dust ( $>86.8 \%)$. with 32 mean concentrations exceeding those of PBDEs. Unlike PBDEs, dust TDCIPP and 33 TPHP levels were not associated with hand wipes. However, hand wipe levels were associated 34 with urinary metabolites. Women also had higher levels of DPHP, but not BDCIPP. BDCIPP and DPHP 37 concentrations were moderately to strongly reliable over five consecutive days (Hoffman et al., 2014). On the other hand, concentrations of TAPs, e.g., tri-n-butyl phosphate (TNBP), triphenyl phosphate (TPHP), tris(2-butoxyethyl) phosphate (TBOEP) and tris(1,3-dichloro-2-propyl) phosphate (TDCIPP), have been found at $\mu \mathrm{g} / \mathrm{g}$ levels in household dust (Bergh et al., 2011; Cequier et al., 2014; Cequier et al., 2015; Dodson et al., 2012).

Results of emission studies are presented for building products, electronic equipment, and automobiles (Wensing et al., 2014). Significant relationships between housing characteristics (e.g., flooring materials and frequency of window opening) and the levels of OPs in the house dust has been established (Araki et al. 2014, Marklund et al. 2003) findings. In summary, distribution patterns of the OPs in Sweden reflects the building materials and the consumer products used in the vicinity. This confirms that floor polish, PVC floor coverings, upholstery, plastic products and electronic equipment act as potential sources.

Comparable average concentrations of OPFRs were obtained in private house dust samples from U.S (Carignan et al., 2013) and Europe (Marklund et al., 2003; Garcia et al., 2007; Bergh et al., 2011, Oceania (e.g., New Zealand) (Ali et al., 2012), , and Kuwait (Ali et al., 2013), in which the predominant compositions were TBOEP, TCIPP, TCEP, TPHP and TDCPP. On the other hand, significantly lower levels of OPFRss were obtained in home dust samples from the Philippines, Pakistan and Egypt (Ali et al., 2013; Kim et al., 2013; Abdallah and Covaci, 2014), this may be related to less strict fire-safety regulations and ongoing usage of PBDE-type FRs in these developing countries (Wei et al. (2015). In Japan, higher OPFRs were reported in domestic dust samples from (Kanazawa et al., 2010; Araki et al., 2014). This was explained by more frequent use of floor polish due to the high percentage of wooden floors in Japanese homes (Wei et al. (2015), This was supported by the finding that wooden floors have higher dust samples of FRs (with a median value of $544 \mathrm{mg} / \mathrm{g}$ ) than that from other types of flooring, e.g., carpeting, tile, stone and tatami (with a median value of $93.1 \mathrm{mg} / \mathrm{g}$ ), which are likely associated with more frequent use of floor polishes (Araki et al., 2014).

For house dust in the USA, higher levels of TDCPP in the dust from the main living areas were moderately correlated to that from the bedrooms, indicating the presence of more upholstered furniture occupied in the main living areas and the potential transport direction of TDCPP within the house (Ingerowski et al., 2001). Similar concentrations were also found among the concentrations of TBOEP, TNBP and TPHP in mattresses and the corresponding floor dusts in New Zealand, implying common emission sources for flooring and mattress dusts (Ali et al., 2012). Compared to Sweden, Spain, Belgium, USA and Japan, the lower concentrations of TCEP, TCIPP, TDCPP and TPHP observed in New Zealand were attributed to to NewZealand's reduced utilization of OPFRs in furniture (Ali et al., 2012). Lower levels of OPs in home dust samples with a sandy texture were likely ascribed to a higher contribution, thus, dilution from the outdoors (Ali et al., 2011, 2013), which was in accordance with the results of considerably lower levels of OPs obtained in houses with a higher frequency of window opening (Araki et al., 2014).

\section{Water}

Flame retardants are also a significant part of ocean pollution; they wash out in the laundry and are carried out to sea. Flame retardants used in furniture and electronics work their way into aquatic food chains, accumulating in organisms from mussels to fish to seals." In fact, men are advised to eat shark and other carnivorous fish like swordfish no more than once a month; pregnant women are told they should never consume these fish. And children? I wouldn't feed my kids fish, especially tuna.

Reports on OPFRs in the outdoor atmospheric environment are still very limited. In the 1990s, OPFRs have been detected in aerosols from Antarctica (Ciccioli et al., 1994) and in pine needles from the Sierra Nevada, U.S. (Aston et al., 1996) as a result of atmospheric transport. Further reports in snow and precipitation (Regnery and Püttmann, 2009, 2010) showed potential wash-out mechanisms from the atmosphere and, more important, potential transport pathways of OPs into the marine environment in addition to riverine discharges. OPFRs were found in the in volcanic lakes in Italy as a result of atmospheric deposition Bacaloni et al. (2008).

The following OPFRs were detected in marine atmosphere: TCEP, TCPP, TDCP, TBEP, TPhP, tris(2-ethylhexyl) phosphate (TEHP) and on TnBP and tri-iso-butyl phosphate (TiBP) which have been shown to be major OPsFR in air, snow and remote lakes in recent studies (Bacaloni et al., 2008; Regnery and Püttmann, 2009, 2010). OPFRs were detected in the atmosphere of the North Sea indicating its importance as an input pathway into the marine environment (Moller et al., 2011). In China, Nine organophosphate esters (OPEs: TCEP, TCPPs, TDCPP, TiBP, TnBP, TEHP, TPP, TPPO, TCPs in airborne particles were measured during a cruise campaign over the northern South Sea (SCS) from September to October 2013. They found the concentration of the total OPEs ( $\sum$ OPEs) was 47.1-160.9 $\mathrm{pg} \mathrm{m}^{-3}$. The dominant OPEs are Chlorinated OPEs and accounting for $65.8-83.7 \%$ of the $\sum$ OPEs. Moreover, the dry deposition input of the $\sum$ OPEs was estimated to be 4.98 ton $\mathrm{y}^{-1}$ in 2013 in a vast area of northern SCS (Lai et al., 2015).

OPFRs were found in the Ruhr River that is one of Europe's most important rivers used for drinking water supply. Among the OP flame retardants, TCPP is the most prominent as the result of phasing out TCEP and TDCP (IAL, 1999). TCPP is used to > 
95\% in construction; thus, it is probable that most of its residues found in surface waters stems from construction activities, either by the handling of rigid foam plates or by usage of liquid spray foam. On this basis, it can be assumed that about $300 \mathrm{~kg} \mathrm{TCPP}$, about $100 \mathrm{~kg}$ TDCP and TCEP each are transported from the River Ruhr to the river Rhine annually. On the other hand, the consumer has to pay for the installation and maintenance of considerable efforts, which the water suppliers have to use to eliminate xenobiotics from the raw water from a river like the Ruhr or the Rhine (Andersen et al., 2004). Generally, similar concentrations have been detected in surface waters all over Europe; i.e., 20 - $200 \mathrm{ng} / \mathrm{l} \mathrm{TCEP;} 200$ - $700 \mathrm{ng} / \mathrm{l} \mathrm{TBEP,} \mathrm{(Fries} \mathrm{and} \mathrm{Puttmann} \mathrm{,} \mathrm{2001).} \mathrm{The} \mathrm{presence}$ of these chemicals may not necessarily mean harm to the population considering drinking water of the Ruhr area, as most of these compounds are probably successfully eliminated by the water purification plants if appropriate technology is applied as lower concentrations were detected in drinking in Germany. In Canada, similar compounds $(0.6-12 \mathrm{ng} / \mathrm{l} \mathrm{TBP}, 0.3-9.2 \mathrm{ng} / \mathrm{l} \mathrm{TCEP}, 0.2-1.2$ ng/l TDCP, $0.9-75 \mathrm{ng} / \mathrm{l} \mathrm{TBEP,} 0.3-2.6 \mathrm{ng} / \mathrm{l} \mathrm{TPP}$ ) were detected in drinking water though (LeBel et al., 1981)

\section{Rivers}

The concentrations of following organophosphate flame retardants, (tris(1,3-dichloro-2-propyl)phosphate, tris(1-chloro-2-propyl) phosphate and tris(2 chloroethyl)phosphate, in certain areas close to Columbia River in Washington state ranged from 3.6 to 82,700 $\mathrm{ng} \mathrm{g}^{-1}$ and 47.1 to $561,000 \mathrm{ng} \mathrm{L}^{-1}$ for the domestic dust and water of wastewater treatment plant, respectively (Schreder et al., 2014). This indicates that these organophosphate flame retardants was added during cleaning process in laundry.

The levels of 7 organophosphate esters flame retardants were studied in public wastewater treatment plants in the Pearl River Delta, South China through collection sludge samples (Zeng et al., 2014). The results indicated that heterogeneous levels among the different wastewater treatment plants with homogenous distribution pattern and predominant concentration of tris(2-butoxyethyl) phosphate and triphenyl phosphate. The mean level of the investigated flame retardants was $420.1 \mu \mathrm{g} / \mathrm{kg}$ dry weight ranging from $96.7 \mu \mathrm{g} / \mathrm{kg}$ to $1312.9 \mu \mathrm{g} / \mathrm{kg}$ dry weight.

The concentration of the some organophosphorus flame retardants in effluents of rivers and the sewage treatment plant were determined (Andresen et al., 2004). The results reveal that the predominance of the studied flame retard in sewage treatment unit and their level were tris-(2-chloro-, 1-methyl-ethyl)-phosphate (20-200 and $400 \mathrm{ng} / \mathrm{L}$ ), tris-(2-chloroethyl)-phosphate (13- 130 and $130 \mathrm{ng} / \mathrm{l}$ ), tris-(2-chloro-, 1-chloromethyl-ethyl)-phosphate (50 and $120 \mathrm{ng} / \mathrm{l})$ and tris-(butoxyethyl)-phosphate (10-200 and 500 $\mathrm{ng} / \mathrm{L}$ ) in in River Ruhr and sewage treatment plant, correspondingly.

The results of analysis of organophosphate ester flame retardants levels in 90 European wastewater treatment plants revealed contamination with many organophosphate ester flame retardants mainly tris(2-chloroisopropyl)phosphate.

The concentrations of the following chlorinated phosphate flame retardants were determined; tris(2-chloroethyl) phosphate, tris(1-chloro-2-propyl) phosphate, and tris(1,3-dichloro-2-propyl) phosphate were $3400 \mathrm{ng} / \mathrm{L}$ and $2400 \mathrm{ng} / \mathrm{L}$, consequently in rivers in southern California receiving discharge of treated public wastewater effluent (Sengupta et al., 2014).

In Germany, Wolschke et al. (2015) reports the occurrence and distribution of organophosphorus flame retardants and plasticizers (OPEs) in the Elbe and Rhine rivers. In this river, TEP $(168 \pm 44 \mathrm{ng} / \mathrm{L}), \mathrm{TDCPP}(155 \pm 14 \mathrm{ng} / \mathrm{L})$ and TCPP $(126 \pm 14 \mathrm{ng} / \mathrm{L})$ identified as the dominant OPEs compounds. They also found an increase in the concentrations and relative contributions of TDCPP to the total level of OPEs relative to previous studies. During the flood event, the concentrations of OPEs were similar to the normal situation, and the mass flux of OPEs appeared to be driven by water discharge.

\section{Sewage Treatment Station}

A comprehensive study was conducted on organophosphorus flame retardants from 11 Swedish sewage treatment stations (Marklund et al., 2005). On the one hand, the chlorinated organophosphorus flame retardants pass untouchable. On the other hand, these stations got rid of alkyl organophosphorus flame retardants more effectively. The most frequently detected organophosphorus flame retardants in both influents and effluents were tris(2-butoxyethyl) phosphate and tributyl phosphate, while tris(2-chloroisopropyl) phosphate ranked after them. Ethylhexyl diphenyl phosphate and tris(2-chloroisopropyl) phosphate represented the majority in both influents and effluents. Moreover, the chief concentration of organophosphorus flame retardants in influents was for tributyl phosphate $\left(52\right.$ microg $\left.\mathrm{L}^{-1}\right)$. The fate of organophosphorus flame retardants was $1 \%$ remained in sewage and degradation of $49 \%$, while the half of them return back to the population.

The levels of four halogenated organophosphorus flame retardants were determined in seawater of three distinct regions in China through collection of 13 samples (Hu et al., 2014). The results revealed that the mean levels of tris(2-chloroethyl) phosphate, tris(2-chloroisopropyl) phosphate tris (1,3-dichloro-2-propyl) phosphate and tris(2,3-dibromopropyl) phosphate were 134.44, 84.12, 109.28 , and $96.70 \mathrm{ng} / \mathrm{L}$, in that order, while the range of the studied halogenated organophosphorus flame retardants was (91.87 $1392 \mathrm{ng} / \mathrm{L}$ ). Positive correlation exist between their concentration and the degree of the pollution which is associated with the chief input of them from wastewater treatment plants effluential waste.

The concentration of following organophosphate flame retardants in sewage treatment plant were determined (Celano et al., 2014). The results revealed the concentration of both tri(chloroisopropyl) phosphate and tributoxyethyl phosphate was above $700 \mathrm{ng} \mathrm{g}^{-1}$, while for triphenyl phosphate the level was $67 \mathrm{ng} \mathrm{g}^{-1}$.

\section{Biota}

Recent studies suggest that OPFRs residue concentrations in body compartments and eggs of exposed wildlife are much lower than reported in abiotic environmental samples including those of tris(2-butoxyethyl) phosphate (TBOEP), TPHP, TCIPP and tris(isobutyl) phosphate. Concentrations of 16 OP triester FRs were found in six body compartments from female herring gulls 
(Larus argentatus; $\mathrm{n}=8$ ) and the separate egg yolk and albumen of their entire clutches of eggs $(\mathrm{n}=16)$, where they were not detectable in liver, blood plasma, and brain samples. There were also large contrasts in concentrations and patterns of these OP triester FRs in fat and muscle, and egg yolk and albumen. (Su et al.,2014).

\section{Occupational Exposure to OPFRs and Health}

Humans are exposed to flame retardants through several routes, including inhalation, ingestion, and skin contact with treated materials. Rodent studies showed that TDCPP is readily absorbed through the skin and gastrointestinal tract (Marklund et al., 2005; Thorvald et al., 2004). Infants and young children have the highest exposure to TDCPP compared to adults, because children spend more time indoors and closer to the floor and they frequently put their hands and other objects into their mouths without washing. Several studies show that TDCPP can accumulate in human tissues. It has been detected in semen, fat, and breast milk (Regnery and Puttman 2010; Hudec et al, 1989, LeBel et al., 1989) and the metabolite bis (1,3-dichloropropyl) phosphate (BDCPP) has been detected in urine (Sundkvist et al., 2010).

Cockpit and cabin air: The role of tricresyl phosphates (TCP) released as a result of malfunction of jet engine which may reach to cabin air resulting in a characteristic odor was investigated (Schindler et al., 2013). This process is known as fume events. Because of TCP's anti-wear and anti-abrasive properties, it is added to improve quality of engine oils (Winder and Michaelis 2005b). Another source of various forms of organophosphates flame retards like TCEP and TCPP can be released from foams of seats and other plastics and TBP and TPP from hydraulic fluids (Solbu et al. 2011). A total of 332 urine samples collected from pilots and members of cabin crew with history of exposure to fumes event were investigated for the presence of phosphate (three isomers) and other four flame retards (dialkyl and diaryl phosphate). Results indicated control level of TOCP isomer among the exposed group except one sample contain slightly higher level of $m$ - and $p$-tricresyl phosphates isomers above the limit for detection. On the one hand, there was a significantly high level of tributyl phosphate (TBP), tris-(2-chloroethyl) phosphate (TCEP) and triphenyl phosphate (TPP) metabolites in urine of exposed group. Also, tris-(2-chloropropyl) phosphate (TCPP) metabolite levels were nearly similar among exposed and non-exposed groups. Thus, this study demonstrated the presence of ORFRs in the urine of flight crew.

The occupational exposure of aircrew to organophosphate flame retardants was assessed by determining their concentrations on both wipe surface and activated charcoal cloths and also though HEPA filters (Solbu et al., 2011). Various types of turbine airplane engine, propeller and helicopters of 47 flights was subjected for this assessment. The results showed that tricresyl phosphate was detected in $4 \%, 39 \%$ and $100 \%$ of day samples, wipes surfaces and HEBA filters, respectively with greater concentration with outflow of engine oil but below limit of detection. Furthermore, tri-n-butyl phosphate was more prevalent and was detected in all day sample.

Some reports found no credible evidence for the involvement of tricresyl phosphate in pathogenesis of aertoxic syndrome (Weiss et al., 2015) in support of a previous study (Schindler et al., 2013).

Neurotoxicity of tri-cresyl phosphates (TCP) may occur below acute toxicity detection level which may explain implicating of TCP in pathogenesis of aerotoxic syndrome even at level below the level of detection (Hausherr et al., 2014). Also, tri-cresyl phosphates induced decline of primary cortical neurons of mouse embryos (E 16.5) cells responding to glutamate without any morphological changes at a very small concentration $(100 \mathrm{nM})$.

The pivotal role of epigenetic in pathogenesis of aerotoxic syndrome has been demonstrated (Reinen et al., 2015), An in vitro study of cell cultures from both Human and rat liver microsomes, and different variant of recombinant human P450 cell cultures showed that both P450 3A4 and 3A5 are associated with strong activation of tri-ortho-cresyl phosphate into its toxic metabolite producing powerful irreversible inhibition of cholinesterase, while 1A2 are associated with weaker transformation. Thus, not the tri-ortho-cresyl phosphate per se exerts the toxic action but its metabolite, the 2-(ortho-cresyl)-4H-1,2,3-benzodioxaphosphoran-2-one which different greatly with P450 1A2 and 3A4 phenotypes. The health hazardous of exposure of aircrew team to organophosphate whose sources were flames retardants and engine leaks was studied using by using the following auto antibodies against seven proteins that are associated with neurodegeneration, microtubule-associated tau proteins, tubulin, neurofilament triplet proteins, microtubule-associated protein-2, glial fibrillary acidic protein (GFAP), myelin basic protein and glial S100B protein (Abou-Donia et al., 2013). Western blotting was used to detect the Immunoglobulin G (IgG) in 34 aircrew team and 12 controlled healthy individuals. Positive correlation existed between exposure of aircrew team to contaminated air and high levels of studied antibodies. In addition, measuring serum level of a pilot, not complaining from these symptoms, before and after flying for 45 hours in ten days demonstrated that post exposure raise in levels of the studied antibodies which were closely related to progressive deterioration of his clinical manifestation. Furthermore, stopping of flying for one year, produced not only improving of his clinical manifestation, but also reduction of levels of previously mentioned antibodies. This study emphasize on the involvement of organophosphates in aerotoxic syndrome

On the other hand, de Ree et al., 2014 reported no association between occupational association between aerotoxic syndrome and tri-ortho-cresyl Phosphate. This conclusion was based on not detecting level of TOCP and other ortho-isomers and presence of low level of non-ortho isomers of tricresyl phosphates inside the cabin. The level of tricresyl phosphate (TCP) was studied in the air of cockpit of three form of military airplanes, fighter trainer, fighter bomber, and cargo transport airplanes after experience of abnormal smell by pilots (Denola et al., 2011). This may result from malfunction of engine and cracks of tubular system leading to leakage of some products of engine oil containing tricresyl phosphate. The sample size was 78 samples of air gathered from 46 airplanes during ignition of engines from both airplanes and ground by sorbent tubes packed with Porapak Q and cellulose filters. The results indicated that there were nine times experiences of smelling smoke during this study; however, all samples were below 
than the limit of detection of $100 \mu \mathrm{g} / \mathrm{m}^{3}$. The concentration of tricresyl phosphate in majority of samples was less than $5 \mu \mathrm{g} / \mathrm{m}^{3}$, while the highest concentration was $51.35 \mu \mathrm{g} / \mathrm{m}^{3}$. Gas chromatography-mass spectrometry technique was used for detection occupational exposure to the following organophosphates flame retardants; tri-isobutyl, triphenyl, tri- $n$-butyl, tri- $m$-cresyl, tri- $o$-cresyl and tri- $p$ cresyl phosphates from hydraulic fluid through combined aerosol and vapor air sampling (Solbu et al., 2007). The study was carried out in various airplane chambers with different concentration of organophosphates flame retardants added to the oils. This study revealed that the air levels of tricresyl phosphate were 0.024 and $0.28 \mathrm{mg} / \mathrm{m}^{3}$, while during maintenance of the airplane, the air levels of tri- $n$-butyl phosphate were 0.061 and $0.072 \mathrm{mg} / \mathrm{m}^{3}$. This study confirmed the occupational exposure to organophosphates flame retardants.

The occupational exposure of loaders and technicians in aviation industry to organophosphate flame retardants from hydraulic and engine oils was determined i288 samples for the following organophosphate flame retardants; tricresyl phosphate, tri-nbutyl phosphate, (DBPP), triphenyl phosphate and dibutyl phenyl phosphate (Solbu et al., 2010). The results revealed that the level of organophosphate flame retardants are below level of detection with predominance tricresyl phosphate level among loaders, higher level was $31 \mathrm{mg} / \mathrm{m}^{3}$. The maximal levels of organophosphate flame retardants for technician and loaders existed during maintenance of wheel well and loading from the airplanes engines, consequently

Airplane maintenance technicians: A pilot study was carried out to investigate the exposure of airplanes maintenance technicians to some organophosphates flame retards as variable concentrations of triphenyl phosphate (TPP) and tributyl phosphate (TBP) that are present in hydraulic fluids and turbine oils (Schindler et al., 2014). Five technicians were assessed for dialkyl and diaryl phosphate metabolites by collecting urine samples before and after their work. The results revealed higher levels of and triphenyl phosphate metabolites, diphenyl phosphate, $(2.9 \mu \mathrm{g} / \mathrm{L}$ and $3.5 \mu \mathrm{g} / \mathrm{L}$, before and after work respectively) than concentration in general population $(0.5 \mu \mathrm{g} / \mathrm{L})$. The urine contained $(12.5 \mu \mathrm{g} / \mathrm{L})$ dibutyl phosphate a metabolite of tributyl phosphate, $(23.5 \mu \mathrm{g} / \mathrm{L}) \mathrm{TBP}$, compared to and $(<0.25 \mu \mathrm{g} / \mathrm{L})$. for control.

The concentration of some of organophosphate flame retardants was determined in 12 sites in Zurich and Switzerland (Hartmann et al., 2004). The tris(2-ethylhexyl) phosphate was detected in all samples, while triphenyl phosphate was detected only in $62 \%$ of samples and the concentrations of both chemicals reaching $3.4 \mathrm{ng} / \mathrm{m}^{3}$. Additionally, the concentration of Tris(2-chloro-isopropyl) phosphate was the greatest among the investigated organophosphate flame retardants accounting for $260 \mathrm{ng} / \mathrm{m}^{3}$.

The concentration in air samples of organophosphorus compounds in 17 different domestic and occupational sites were determined (Marklund et al., 2005). Tris(chloropropyl) phosphate and tris(2-chloroethyl) phosphate represented the majority of the studied organophosphorus compounds with concentration ranging between 0.4 and $730 \mathrm{ng} / \mathrm{m}^{-3}$ followed by tributyl phosphate with concentration ranging between $0.5-120 \mathrm{ng} \mathrm{m}^{-3}$. The air samples concentrations of organophosphorus compounds in public areas were about three to fourth folds of domestic areas.

Office Dust: Tris(1,3-dichloro-2-propyl) phosphate level was detected in dust of office workers' homes, offices and vehicles and urinary level of its metabolite, bis(1,3-dichloro-2-propyl) phosphate among 29 office workers (Carignan et al., 2013). Significantly higher level of Tris(1,3-dichloro-2-propyl) phosphate were determined in their vehicle $(12.5 \mu \mathrm{g} / \mathrm{g})$ and offices $(6.06 \mu \mathrm{g} / \mathrm{g})$ than observed in their homes $(4.21 \mu \mathrm{g} / \mathrm{g}$ and $1.40 \mu \mathrm{g} / \mathrm{g}$ in living and bedrooms respectively ). While level of this metabolites for workers in newer buildings was about the quarter of workers in the older ones. This study emphasizes occupational exposure of office workers to OPCFR from polyurethane foam.

Electronic Supplies, Clothes Shops and University: The levels of triphenyl phosphate in the breathing zones of 18 computer video display units in small offices were $100 \mathrm{ng} / \mathrm{m}^{3}, 50 \mathrm{ng} / \mathrm{m}^{3}$ and $10 \mathrm{ng} / \mathrm{m}^{3}$ after 1day, 7 days and 183 days, respectively, of using brand new computer video display units (Carlsson et al., 2002)

Organophosphate compound flame retardants were found to be the major contaminants in dust but not in serum in the study conducted in Faisalabad, Pakistan (Ali et al., 2014). Dust and serum samples were collected from electronic supplies, clothes shops and university, respectively. The highest dust levels were detected in University followed by clothes shops, while dust in electronic supplies was the lowest level among the investigated organophosphate flame retardants.

The occupational exposure of some organophosphate and brominated flame retardant were investigated through assessment of their concentration in air of recycling electronics factories and offices containing computers (Sjödin et al., 2001). The uppermost levels are detected in recycle electronic factories mainly at dismantling partition with predominance of triphenyl phosphate among the studied flame retardants with level of $58 \mathrm{pmol} / \mathrm{m}^{3}$.

Furniture: The Respiratory and dermal occupational exposure of OPFRs in furniture shop, a circuit board plant, two electronics dismantling services, a computer classroom, and offices through collection air samples were investigated for respiratory route, and patch and hand wash samples, for dermal route of exposure (Mäkinen et al., 2009). The results indicated that triphenyl phosphate, tris(2-chloroethyl) phosphate, and tris(2-chloroisopropyl) phosphate were the most prominent in this study with the highest concentration at electronics dismantling services (2.9 -3.8 microg $\left./ \mathrm{m}^{3}\right)$. For the dermal exposure, the level of organophosphrus flame retardants were $\left(1.5\right.$ and $\left.24 \mathrm{ng} / \mathrm{cm}^{2}\right)$ an 3.5 and $34 \mathrm{microg} /$ two hands) for patch and hand wash samples, consequently. Thus, this study stresses on the crucial dermal route of occupational exposure. 


\section{Conclusions}

Although the use of a new generation of chemicals known as Organophosphorus Flame Retardants (OPFRs) is a worthy goal for controlling household fires on one hand, the other hand, it is also important to control or prevent their toxic effects. Recent studies have raised health concerns about exposure to these chemicals, which are commonly found in footwear, electronics, sleeping bags and many other consumer products. Although the chemical industry claims that these materials are safe, recent studies have questioned whether that is in fact so.

In 1970s a controversy took place for the use of Tris or Tris (2,3-dibromopropyl) phosphate as a flame retardant in children's pajamas. Its purpose was to protect children from fire. Follow-up studies, however, concluded that Tris is a mutagen. Promptly, the federal Consumer Product Safety Commission prohibited its use in the sleepwear. As time passed, Tris made its way, along with an array of other chlorinated and brominated phosphorus flame retardants, into the furniture found in most American homes.

In the meantime, children's sleepwear must still be treated with flame retardants. Small children, known to put almost anything in their mouths, are particularly vulnerable as they play on floors that have veils of chemically tainted dust. Some of the reported effects of OPFRs are on the developing nervous system and effects on the developing reproductive system. In a population of children that have been exposed to the flame retardants, those children have lower I.Q and more difficulty in learning. The number of reported home fires has dropped by 50 percent since these products were introduced to the market. Other factors, though, also explain the decline in house fires. For one thing, a principal culprit in such fires has long been carelessness with cigarettes. But smoking habits have greatly changed; the share of American adults who smoke dropped to 17 percent in 2014 from 42 percent in 1965, according to the Centers for Disease Control and Prevention.

Laws and regulations governing the use and safety of OPCFRs are never permanent; they change as our knowledge expands. The society has to apply the results of risk-benefit assessments regarding the use of OPCFRs based on the available information by regulating their use. It should be remembered, that the government will "step in only after a substance's potential for harm has been demonstrated." This is a very high standard to reach if case and cohort studies are excluded because neither meets scientific criteria that correlation is not causation.

\section{References}

1. Abdallah, M.A., Covaci, A. Organophosphate flame retardants in indoor dust from Egypt: implications for human exposure. (2014) Environ Sci Technol 48(9): 4782-4789.

2. Abdel-Rahman, A.A., Jensen, K.F., Farr, C.H., et al. Daily treatment of triphenylphosphine (TPP) produces organophosphorus-induced delayed neurotoxicity (OPIDN). (1997) Toxicologist 36(19).

3. Abou-Donia, M.B. Organophosphorus Ester-Induced Delayed Neurotoxicity. (1981) Annu Rev Pharmacol Toxicol 21: 511-548.

4. Abou-Donia, M.B. Organophosphorus pesticides. In: Chang LW, Dyer RS (Eds). New York: Marcel Dekker (1994) Handbook of Neurotoxicology 419-447.

5. Abou-Donia, M.B. Organophosphorus pesticides. In: Chang LW, Dyer RS (Eds). New York: Marcel Dekker (1995) Handbook of toxicology 419-473.

6. Abou-Donia, M.B. Organophosphorus Ester-Induced Chronic Neurotoxicity. (2003) Archives of Environmental Health 58(8): $484-497$.

7. Abou-Donia, M.B. Organophosphate Ester-Induced Chronic Neurotoxicity. (2005) The J Occup Health and Safe Australia and New Zealand 21(5): 408-432.

8. Abou-Donia, M.B., Abou-Donia, M.M., El-Masry, E.M., et al. Autoantibodies to nervous system-specific proteins are elevated in sera of flight crew members: biomarkers for nervous system injury. (2013) J Toxicol Environ Health 76(6): 363-380.

9. Abou-Donia, M.B., Lapadula, D.M. Mechanisms of Organophosphorus Ester-Induced Delayed Neurotoxicity: Type I and Type II. (1990) Annu Rev Pharmacol Taxicol 30: 405-440.

10. Abou-Donia, M.B., Patton, S.E., Lapadula, D.M. Possible role of endogenous protein phosphorylation in organophosphorus compound-induced delayed neurotoxicity. Proceedings of the Symposium on: (T. Narahashi, Ed) (1984) Cellular and Molecular Neurotoxicity, Raven Press, NY 265-283.

11. Abou-Donia, M. B., Preissig, S. H. Delayed neurotoxicity of leptophos: Toxic effects on the nervous system of hens. (1976) Toxieol Appl Pharmacol 35(2): 269-282.

12. Abou-Donia, M.B., Viana, M.E., Gupta, R.P., et al. Enhanced calmodulin binding concurrent with increased kinase-dependent phosphorylation of cytoskeletal proteins following a single subcutaneous injection of diisopropyl phosphorofluoridate in hens. (1993) Neurochem Int 22(2): $165-173$.

13. Abou-Donia, M.B., Wilmarth, K.R., Jansen, K.F., et al. Triphenyl phosphine (TPP): a type III organophosphorous compound-induced delayed neurotoxic agent OPIDN). (1996) Toxicologist 30: 311.

14. ACGIH. Tributyl phosphate. In: Documentation of the threshold limit values and biological exposure indices. 7th ed. Cincinatti, Ohio (2001) American Conference of Governmental Industrial Hygienists.

15. Agency for Toxic Substances and Disease Registry. Toxicological profile for phosphate ester flame retardants. (2012) Atlanta, GA.

16. Ali, N., Mehdi, T., Malik, R.N., et al. "Levels and profile of several classes of organic contaminants in matched indoor dust and serum samples from occupational settings of Pakistan”. (2014) Environ Pollut 193: 269-276.

17. Alm, H., Scholz, B. Developmental neurotoxicity of PBDEs: mechanisms and implications. (2010) In: Merlani, P.B. (Ed.) Flame Retardants: Functions, Properties and Safety, Nova Science Publishers, New York, 1-40.

18. Aldridge, W.N. Tricresyl phosphate and cholinesterase. (1954) Biochem J 56(2): 185-189.

19. Ali, N., Ali, L., Mehdi, T., et al. Levels and profiles of organochlorines and flame retardants in car and house dust from Kuwait and Pakistan: implication for human exposure via dust ingestion. (2013) Environ Int 55: 62-70. 
20. Ali, N., Dirtu, A.C., Van den Eede, N., et al. Occurrence of alternative flame retardants in indoor dust from New Zealand indoor sources and human exposure assessment. (2012) Chemosphere 88(11): 1276-1282.

21. Ali, N., Van den Eede, N., Dirtu, A.C., et al. Assessment of human exposure to indoor organic contaminants via dust ingestion in Pakistan. (2011) Indoor Air 22(3):200-211.

22. Andresen, J.A., Grundmann, A., Bester, K. Organophosphorus flame retardants and plasticisers in surface waters. (2004) Sci Total Environ 332(1-3): 155-166.

23. Araki, A., Saito, I., Kanazawa, et al. Phosphorus flame retardants in indoor dust and their relation to asthma and allergies of inhabitants. (2014) Indoor Air 24(1): 3-15.

24. Aring, C. U. The systemic nervous affinity of triorthocresyl phosphate (Jamaica Ginger Palsy). (1942) Brain 65: 34-47.

25. Aston, L.S., Noda, J., Seiber, J.N., et al. Organophosphate flame retardants in needles of Pinus Ponderosa in the Sierra Nevada foothills. (1996) Bull Environ Contam Toxicol 57(6): 859-866.

26. Bacaloni, A., Cucci, F., Guarino, C., et al. Occurrence of organophosphorus flame retardant and plasticizers in three volcanic lakes of central Italy. (2008) Environ Sci Technol 42(6):1898-1903.

27. Behra, M., Etard, C., Cousin, X., et al. The use of zebrafish mutants to identify secondary target effects of acetylcholine esterase inhibitors. (2004) Toxicol Sci 77(2): 325-333.

28. Bergh, C., Luongo, G., Wise, S., et al. Organophosphate and phthalate esters in standard reference material 2585 organic contaminants in house dust. (2012) Anal Bioanal Chem 402: 51-59.

29. Biernat, J., Gustke, N., Drewes, G., et al Phosphorylation of Ser262 strongly reduces binding of tau to microtubules: distinction between PHFlike immunoreactivity and microtubule binding. (1993) Neuron 11(1) : 153-163.

30. Bloch, H., Hottinger, A. Uber die spezifitat der cholinesterase-hemmung durch tri-o-kresyl phosphat. (2004) Helvetica Chimica Acta 26(1): $142-155$.

31. Bollmann, U.E., Moller, A., Xie, Z.Y., et al. Occurrence and fate of organophosphorus flame retardants and plasticizers in coastal and marine surface waters. (2012) Water Res 46(2): 531-538.

32. Bradley, M., Rutkiewicz, J., Mittal, K., Fernie, K,. In ovo exposure to organophosphorous flame retardants: survival, development, neurochemical, and behavioral changes in white leghorn chickens. (2015) Neurotoxicol teratology 52(Pt B): 228-235.

33. Bradman, A., Castorina, R., Gasper, F. Flame retardant exposures in California early childhood. (2014) Chemosphere 116: 61-66.

34. Brandsma, S.H., Leonards, P.E., Leslie, H.A., et al. Tracing organophosphorous and brominated flame retardants and plasticizers in an estuarine food web. (2015) Sci Total Environ.505: 22-31.

35. Brunden, K.R., Trojanowski, J.Q., Lee, V.M. Evidence that non-fibrillar tau causes pathology linked to neurodegeneration and behavioral impairments. (2008) J Alzheimers Dis 14(4): 393-399.

36. Buee, L., Bussie 'rec, T., Bue'e-Scherrerb, V., et al. Tau protein isoforms, phosphorylation and role in neurodegenerative disorders. (2000) Brain Res Rev 33(1): $95-130$.

37. Carignan, C.C., McClean, M.D., Cooper, E.M., et al. Predictors of tris(1,3-dichloro-2-propyl) phosphate metabolite in the urine of office workers. (2013) Environ Int 55: 56-61.

38. Carlsson, H., Ulrika, N., Conny, Ö. Video display units: an emission source of the contact allergenic flame retardant triphenyl phosphate in the indoor environment. (2000) Environ Sci technol 34(18): 3885-3889.

39. Ciccioli, P., Cecinato, A., Brancaleoni, E., et al. Chemical composition of particulate organic matter (POM) collected at Terra Nova Bay in Antarctica. (1994) Int J Environ Anal Chem 55(1-4): 47-59.

40. Cooper, E.M., Covaci, A., van Nuijs, A.L.N. et al. Analysis of the flame retardant metabolites bis(1,3-dichloro-2-propyl) phosphate (BDCPP) and diphenyl phosphate (DPP) in urine using liquid chromatography-tandem mass spectrometry. (2011) Anal Bioanal Chem 401(7): $2123-2132$.

41. Carrington, C. D., Abou-Donia, M.B. Triphenyl phosphite neurotoxicity in the hen: inhibition of neurotoxic esterase and a lack of prophylaxis by phenylmethylsulfonyl fluoride. (1988) Arch Toxicol 62(5): 375-380.

42. Carrington, C.D., Brown, H.R, Abou-Donia, M.B. Histopathological assessment of triphenyl phosphite neurotoxicity in the hen. (1988) Neurotoxicology 9(2): 223-234.

43. Carrington, C.D., Lapadula, D.M., Othman, M. Assessment of the delayed neurotoxicity of tributyl phosphate, tributoxyethyl phosphate, and dibutylphenyl phosphate.(1989) Toxicol Indust Health 6(3-4): 415-423.

44. Carrington, C.D., Lapadula, D.M., Othman, M. Assessment of the delayed neurotoxicity of tributylphosphate, tributoxyethyl phosphate, and dibutylphenyl phosphate. (1990) Toxicol Ind Health 6(3-4):415-23

45. Cavanagh, J.B. The significance of the "dying back" process in experimental and human neurological disease. (1964) Intl Rev Exp Pathol 3: 219-267.

46. Chapin, R.E., Phelps, J.L., Somkuti, et al. The interaction of Sertoli and Leydig cells in the testicular toxicity of tri-o-cresyl phosphate. (1990) Toxicol Appl Pharmacol 104(3): 483-95.

47. Cequier, E., Sakhi, A.K., Marce, R.M., et al. Human exposure pathways to organophosphate triesters - A biomonitoring study of mother-child pairs.(2015) Environ Int 75: 159-165.

48. Cleveland, D.W., Hwo, S.Y., Kirschner, M.W., Physical and chemical properties of purified tau factor and the role of tau in microtubule assembly. (1977) J Mol Biol 116(2):227-247.

49. Cleveland, D.W., Hwo, S.Y., Kirschner, M.W., Purification of tau, a microtubule-associated protein that induces assembly of micro- tubules from purified tubulin. (1977) J Mol Biol 116(2): 207-225.

50. Coburn, C.G., Curras-Collazo, M.C., Kodavanti, P.R.S. In vitro effects of environmentally relevant polybrominated diphenyl ether (PBDE) congeners on calcium buffering mechanisms in rat brain. (2008) Neurochem Res 33(2): 355-364.

51. Costa L.G., Giordano, G. Developmental neurotoxicity of polybrominated diphenyl ether (PBDe) flame retardants. (2007) Neurotoxicology 28(6): 1047-1067.

52. Costa, L.G., Huang, S.C., Giordano, G. Oxidative stress as a potential mechanism for developmental neurotoxicity of polybrominated diphenyl ether (PBDE) flame retardants. (2010) In: Merlani, P.B. (Ed.) Flame Retardants: Functions, Properties and Safety, Nova Science Publishers, New York 101-115.

53. Costa, L.G., Pellacani, C., Dao, K., et al. The brominated flame retardant BDE-47 causes oxidative stress and apoptotic cell death in vitro and in vivo in mice. (2015) Neurotoxicology 48: 68-76. 
54. Crump, D., Chiu, S., Kennedy, S.W. Effects of tris(1,3-dichloro-2-propyl) phosphate and tris(1-chloropropyl) phosphate on cytotoxicity and mRNA expression in primary cultures of avian hepatocytes and neuronal cells. (2012) Toxicol Sci 126(1): 140-148.

55. Carignan, C.C., McClean, M.D., Cooper, E.M., et al. Predictors of tris(1,3-dichloro-2-propyl) phosphate metabolite in the urine of office workers. (2013) Environ Int 55: 56-61.

56. de Ree, Hans, van den Berg, M., Brand, T., et al. "Health risk assessment of exposure to TriCresyl Phosphates (TCPs) in aircraft: A commentary." (2014) Neurotoxicology 45: 209-215.

57. Denola, G., Hanhela, P.J., Mazurek, W. Determination of tricresyl phosphate air contamination in aircraft.” (2011) Ann Occup Hyg 55(7): $\lceil 710-722$.

58. Dickhoff Walton, W., Darling Douglas, S. "Evolution of Thyroid Function and Its Control in Lower Vertebrates". (1983) American Zoologist 23(3): 697-707.

59. Dishaw L, V., Powers, C.M., Ryde, I.T., et al. "Is the PentaBDE replacement, tris (1,3-dichloro-2-propyl) phosphate (TDCPP), a developmental neurotoxicant? Studies in PC12 cells." (2011) Toxicol Appl Pharmacol 256(3): 281-289.

60. Dishow, L.V, Hunter, D.L, Padnos, B., et al. Developmental exposure to organophosphate flame retardants elicits overt toxicity and alters behavior in early life stage zebrafish (Danio rerio). (2014) Toxicol Sci 142(2): 445-54.

61. Dodson, R.E., Perovich, L.J., Covaci, A., et al. After the PBDE phase-out: A broad suite of flame retardants in repeat house dust samples from California. (2012) Environ Sci Technol 46(24): 13056-13066.

62. Fries, E., Puttmann, W. Occurrence of organophosphate esters in surface water and ground water in Germany. (2001) J Environ Monit 3(6): $621-626$.

63. Earl, C.J., Thompson, R.H.S. The inhibitory action of tri-ortho-cresyl phosphate on cholinesterases. (1952) Br J Pharmacol Chemother 7(2): 261-269.

64. Earl, C.J., Thompson, R.H.S. Cholinesterase levels in the nervous system in tri-ortho-cresyl phosphate poisoning. (1952) Br J Pharmacol Chemother 7(4): 685-694.

65. Eaton, D.L., Daroff, R.B., Autrup, H., Bridges, J., et al. Review of the toxicology of chlorpyrifos with an emphasis on human exposure and neurodevelopment. (2008) Crit Rev Toxicol 38(2): 1-125.

66. Ellis, J., Shah, M., Kubacha, M.K., et al., Determination of organophosphorus fire retardants and plasticizers in wastewater samples using MAE-SPME with GC-ICPMS and GC-TOFMS detection. (2007) J Environ Monit 9: 1329-1336

67. Eldefrawi, A.T., Mansour, N.A., Brattsten, L.B., et al. "Further toxicologic studies with commercial and candidate flame retardant chemicals. Part II". (1977) Bull Environ Contam Toxicol 17(6): 720-726.

68. Eskenazi, B., Chevrier, J., Rauch, S.A., et al. In utero and childhood polybrominated diphenyl ether (PBDE) exposures and neurodevelopment in the CHAMACOS study. (2015) Environmental Hazards and Neurodevelopment 285-304.

69. Fisk, P.R., Girling, A.E., Wildey, R.J. Prioritisation of Flame Retardants for Environmental Risk Assessment. (2003) Produced for Environment Agency, United Kingdom.

70. Farahat, A., Crump, D., Chiu, S., et al. In Ovo effects of two organophosphate flame retardants--TCPP and TDCPP--on pipping success, development, mRNA expression, and thyroid hormone levels in chicken embryos. (2013) Toxicol Sci 134(1): 92-102.

71. Farhat, Amani., Doug Crump., Suzanne Chiu., et al. "In Ovo effects of two organophosphate flame retardants-TCPP and TDCPP-on pipping success, development, mRNA expression, and thyroid hormone levels in chicken embryos.” (2013) Toxicol Sci 134(1): 92-102.

72. Flaskos, J., McLean, W.G., Hargreaves, A.J. The toxicity of organophosphate compounds towards cultured PC12 cells. (1994) Toxicol Lett 70(1): 71-76.

73. Freudenthal, R.I., Henrich, R.T. "Chronic toxicity and carcinogenic potential of tris-(1, 3-dichloro-2-propyl) phosphate in Sprague-Dawley rat". (2000) Int J Toxicol 19(2): 119-125.

74. Gold, M.D., Blum, A., Ames, B.N. "Another Flame Retardant, Tris- (1,3-Dichloro-2-Propyl) Phosphate, and Its Expected Metabolites Are Mutagens”. (1978) Science 200(4343): 785-787.

75. Gant, D.B., Eldefrawi, M.E., Eldefrawi, A.T. Action of organophosphates on GABAA receptor and voltage-dependent chloride channels. (1987) Fundam Appl Toxicol 9(4): 698-704.

76. Garcia, M., Rodriguez, I., Cela, R. Microwave-assisted extraction of organophosphate flame retardants and plasticizers from indoor dust samples. (2007) J Chromatogr A 1152(1-2): 280-286.

77. Giordano, G., Kavanagh, T.J., Costa, L.G. Neurotoxicity of a polybrominated diphenyl ether mixture (DE-71) in mouse neurons and astrocytes is modulated by intracellular glutathione levels. (2008) Toxicol Appl Pharmacol 232(2): 161-168.

78. Gupta, R.P., Abou-Donia, M.B. In vivo and in vitro effects of diisopropyl phosphorofluoridate (DFP) on the rate of hen brain tubulin polymerization. (1994) Neurochem Res 19(4): 435-444.

79. Gupta, R.P, Abou-Donia, M.B. Tau proteins-enhanced Ca2+/calmodulin (CaM)-dependent phosphorylation by the brain supernatant of diisopropyl phosphorofluoridate (DFP)-treated hen: tau mutants indicate phosphorylation of more amino acids in tau by CaM kinase II. (1998) Brain Res 813(1): 32-43.

80. Hartmann Paul, C., Daniel Bürgi., Walter Giger. “Organophosphate flame retardants and plasticizers in indoor air.” (2004) Chemosphere 57(8): 781-787.

81. Hausherr Vanessa., van Thriel, C., Krug A., et al. "Impairment Of Glutamate Signaling In Mouse Central Nervous System Neurons In Vitro By Tri-O-Cresyl Phosphate (TOCP) At Non-Cytotoxic Concentrations." (2014) Toxicol Sci 142(1): 274-284.

82. Hendriks, H.S., van Kleef, R.G., Westerink, R.H. Modulation of human $\alpha 4 \beta 2$ nicotinic acetylcholine receptors by brominated and halogen-free flame retardants as a measure for in vitro neurotoxicity. (2012) Toxicol Lett 213(2): 266-274.

83. Hendriks, H.S., Meijer, M., Muilwijk, M., et al. A comparison of the in vitro cyto and neurotoxicity of brominated and halogen free flame retardants: prioritization in search for safe(r) alternatives. (2014) Arch Toxicol 88(4): 857-869.

84. Healy, C.E., Beyrouty, P.C., Broxup, B.R. Acute and subchronic neurotoxicity studies with tri-N butyl phosphate in adult Sprague-Dawley rats. (1995) Am Ind Hyg Assoc J 56(4): 349-355.

85. Hendriks, H.S., van Kleef, R.G., van den Berg, M., et al. Multiple novel modes of action involved in the in vitro neurotoxic effects of tetrabromobisphenol-A. (2012) Toxicol Sci 128(1): 235-246.

86. Hu, X., Hu, D., Xu, Y. Effects of tetrabrominated diphenyl ether and hexabromocyclododecanes in single and complex exposure to hepatoma 
HepG2 cells. (2009) Environ Toxicol Pharmacol 27(3): 327-337.

87. Hu, X.Z., Xu, Y., Hu, D.C., et al. Apoptosis induction on human hepatoma cells HepG2 of decabrominated diphenyl ether (PBDE-209). (2007) Toxicol Lett 171(1-2): 19-28.

88. Huang, S.C., Giordano, G., Costa, L.G. Comparative cytotoxicity and intracellular accumulation of five polybrominated diphenyl ether congeners in mouse cerebellar granule neurons. (2010) Toxicol Sci 114(1): 124-132.

89. IAL Consultants. IAL market report. The European Flame Retardant Chemical Industry 1998. London: IAL Consultants; 1999.

90. Illis, L., Patangia, G.N., Cavanagh, J.B. Boutons terminaux and triortho- cresyl phosphate neurotoxicity. (1966) Exp Neurol 14(2): 160-74.

91. Ingerowski, G., Friedle, A., Thumulla, J. Chlorinated ethyl and isopropyl phosphoric acid triesters in the indoor environment - an inter-laboratory exposure study. (2001) Indoor Air 11(3): 145-149.

92. IPCS. Environmental Health Criteria 209. Flame retardants: tris(chloropropyl) phosphate and tris(2-chloroethyl) phosphate. (1998) Geneva: World Health Organization, International Programme on Chemical Safety.

93. IPCS. Environmental Health Criteria 218. Flame retardants: tris(2-butoxyethyl) phosphate, tris(2-ethylhexyl) phosphate and tetrakis(hydroxymethyl) phosphonium salts. (2000) Geneva: World Health Organization, International Programme on Chemical Safety. 130

94. Iqbal, K., Liu, F., Gong, C.X., et al. Mechanisms of tau-induced neurodegeneration. (2009) Acta Neuropathol 118(1): 53-69.

95. James, K. A.C., Austin, L. The effect of DFP on axonal transport of protein in chicken sciatic nerve. (1970) Brain Res 18(1):192-94.

96. Janke, C., kneussel, M. Tubulin post-translational modifications: encoding functions on the neuronal microtubule cytoskeleton. (2010) Trends in Neurosciences 33(8): 362-372.

97. Jia, H., Wang, J., Lin, F., et al. TPPi as a flame retardant for rechargeable lithium batteries with sulfur composite cathodes. (2014) Chem Commun (Camb) 50(53): 7011-7013.

98. Johannsen, F.R., Wright, P.L., Gordon, D.E., et al. Evaluation of delayed neurotoxicity and dose-response relationships of phosphate esters in the adult hen. (1977) Toxicol Appl Pharmacol 41(2): 291-304.

99. Johnson, M.K. Delayed neurotoxic action of some organophosphorus compounds. (1969) Br Med Bull 25(3): 231-235.

100. Kanjee, U., Gutsche, I., Ramachandran, S., et al. The enzymatic activities of the Escherichia coli basic aliphatic amino acid decarboxylases exhibit a pH zone of inhibition. (2011) Biochemistry 50(43): 9388-9398.

101. Kamata, E., Naito, K., Nakaji, Y., et al. [Acute and subacute toxicity studies of tris (1,3-dichloro-2-propyl) phosphate on mice]. (1989) Eisei Shikenjo Hokoku (107): 36-43.

102. Laham, S., Szabo, J., Long, G. Short-term neurotoxicity studies on tributoxyethyl phosphate orally administered to Sprague-Dawley rats. (1984) Chemosphere 13(7): 801-812.

103. Laham, S., Szabo, J., Long, G., et al. Dose-response toxicity studies on tributoxyethyl phosphate orally administered to Sprague-Dawley rats. (1985) Am Ind Hyg Assoc J 46(8): 442-448.

104. Lai, S., Xie, Z., Song, T., et al. Occurrence and dry deposition of organophosphate esters in atmospheric particles over the northern South China Sea. (2015) Chemosphere 127: 195-200.

105. LeBel, G.L., Williams, D.T., Berard, D. Triaryl/alkyl phosphate residues in human adipose autopsy samples from six Ontario municipalities. (1989) Bull Environ Contam Toxicol 43(2): 225-230.

106. Lehning, E.J., Tanaka, Jr D., Bursian, S.J. Triphenyl phosphite and diisopropyl phosphorofluoridate produce separate and distinct axonal degeneration patterns in the central nervous system of the rat. (1996) Fundam Appl Toxicol 29(1): 110-118.

107. Leterrier, J.F., Liem, R.K., Shelanski, M.L. Interactions between neurofilaments and microtubule-associated proteins: a possible mechanism for intraorganellar bridging. (1982) J Cell Biol 95(3): 982-986.

108. LeVay, S., Meier, C., Glees, P. Effects of tri-ortho-cresyl phosphate on spinal ganglia and peripheral nerve of chicken. (1971) Acta Neuropathol 17(2): 103-113.

109. Lim, S., Haque, M.M., Kim, D., et al. Cell-based Models to Investigate Tau Aggregation. (2014) Comput Struct Biotechnol J 12(20-21): 7-13. 110. Li, J., Yu, N., Zhang, B., et al. Occurrence of organophosphate flame retardants in drinking water from China. (2014) Water Res 54: 53-61.

111. Lindwall, G., Cole, R.D. Phosphorylation affects the ability of tau protein to promote microtubule assembly. (1984) J Biol Chem 259(8): 5301-5305.

112. Liu, X., Ji, K., Choi, K. Endocrine disruption potentials of organophosphate flame retardants and related mechanisms in H295R and MVLN cell lines and in zebrafish. (2012) Aquat Toxicol 114-115: 173-181.

113. MacFarland, H.N., Punte, C.L. Jr. Toxicological studies on tri-(2-ethylhexyl)-phosphate. (1966) Arch Environ Health 13(1): 13-20.

114. Mäkinen, M.S., Makinen, M.R., Koistinen, J.T., et al. Respiratory and dermal exposure to organophosphorus flame retardants and tetrabromobisphenol A at five work environments. (2009) Environ Sci Technol 43(3): 941-947.

115. Marklund, A., Andersson, B., Haglund, P. Screening of organophosphorus compounds and their distribution in various indoor environments. (2003) Chemosphere 53(9): 1137-1146.

116. Marklund, A., Andersson, B., Haglund, P. Organophosphorus flame retardants and plasticizers in Swedish sewage treatment plants. (2005) Environ Sci Technol 39(19): 7423-7429.

117. McGee, S.P., Cooper, E.M., Stapleton, H.M., et al. Early Zebrafish Embryogenesis Is Susceptible to Developmental TDCPP Exposure. (2012) Environ Health Perspect 120(11): 1585-1591.

118. McGee, S.P., Cooper, E.M., Stapleton, H.M., et al. Early zebrafish embryogenesis is susceptible to developmental TDCPP exposure. (2012) Environ Health Perspect 120: 1585-1591.

119. Meeker, J.D., Cooper, E.M., Stapleton, H.M., et al. Urinary metabolites of organophosphate flame retardants: temporal variability and correlations with house dust concentrations. (2013) Environ Health Perspect 121(5): 580-585.

120. Meeker, J.D., Stapleton, H.M. House dust concentrations of organophosphate flame retardants in relation to hormone levels and semen quality parameters. (2010) Environ Health Perspect 118(3): 318-323.

121. Miyata, Y., Hoshi, M., Nishida, E., et al. Binding of microtubule-associated protein 2 and tau to the intermediate filament reassembled from neurofilament 70-kDa subunit protein. Its regulation by calmodulin. (1986) J Biol Chem 261(28): 13026-13030.

122. Moller, A., Sturm, R., Xie, Z., et al. Organophosphorus flame Retardants and plasticizers in airborne particles over the Northern Pacific and Indian Ocean toward the polar regions: evidence for global occurrence. (2012) Environ Sci Technol 46(6): 3127-3134.

123. Moller, A., Xie, Z., Caba, A., et al. Organophosphorus flame retardants and plasticizers in the atmosphere of the North Sea. (2011) Environ Pollut 159(12): 3660-3665. 
124. National Toxicology Program. Tris(2,3-dibromopropyl) phosphate. (2011) Rep Carcinog 12:428-429.

125. Ni, Y., Kumagai, K., Yanagisawa, Y. Measuring emissions of organophosphate flame retardants using a passive flux sampler. (2007) Atmos Environ 41(15): 3235-3240.

126. NICNAS. Trisphosphates. Priority existing chemical assessment report No.17. Canberra, Australia: National Industrial Chemicals Notification and Assessment Scheme, June 2001.

127. NTP. Toxicology and carcinogenesis studies of tris(2-ethylhexyl) phosphate in F344/N rats and B6C3F1 mice (gavage studies). (1984) National Toxicology Program, Technical report series. No. 274. 178

128. O'Callahan, J.P. Neurotoxic esterase: not so toxic? (2003) Nat Genet 33(4):437-438.

129. O'Connor, T.M., O'Halloran, D.J., Shanahan, F. The Stress response and the hypothalamic-pituitary adrenal axis: from molecule to melanchola. (2000) QJM 93(6): 323-333.

130. OSPAR. Certain brominated flame retardants - polybrominated diphenyletherspolybrominated biphenyls, hexabromo cyclododecane. 2001(2004 updated) OSPAR Commission.

131. Ramsden, J.J. On the proportion of ortho isomers in the tricersyl phosphates contained in jet oil. (2013) J Biol Chem Phys 13(2): 69-72.

132. Patton, S.E., O'Callaghan, J.P., Miller, D.B., et al. Effect of oral administration of tri-o-cresyl phosphate on in vitro phosphorylation of membrane and cytosolic proteins from chicken brain. (1983) J Neurochem 41(3): 897-901.

133. Patton, S.E., Lapadula, D.M., Abou-Donia, M.B. Relationship of tri-o-cresyl phosphate-induced delayed neurotoxicity to enhancement of in vitro phosphorylation of hen brain and spinal cord. (1986) J Pharmacol Exp Ther 239(2): 597-605.

134. Pleasure, D.E., Mishler, K.C., Engel, W.K. Axonal transport of proteins in experimental neuropathies. (1969) Science 166(3904): $524-525$.

135. Prineas, J. The pathogenesis of dying-back polyneuropathies. I. An ultrastructural study of experimental tri-ortho-cresyl phosphate intoxication in the cat. (1969) J Neuropathol Exp Neurol 28(4): 571-597.

136. Reddy, P.H. Abnormal tau, mitochondrial dysfunction, impaired axonal transport of mitochondria, and synaptic deprivation in Alzheimer's disease. (2011) Brain Res 1415: 136-148.

137. Reichert, B.L., Abou-Donia, M.B. Inhibition of fast axoplasmic transport by delayed neurotoxic organophosphorus esters: A possible mode of action. (1980) Mol Pharmacol 17(1): 56-60.

138. Regnery, J., Püttmann, W. Organophosphorus flame retardants and plasticizers in rain and snow from middle Germany. (2009) CLEAN-Soil, Air. Water 37(4-5): 334-342.

139. Schindler, B.K., Weiss, T., Schütze, A., et al. Occupational exposure of air crews to tricresyl phosphate isomers and organophosphate flame retardants after fume events. (2013) Arch Toxicol 87(4): 645-648.

140. Schindler, B.K., Koslitz, S., Weiss, T., et al. Exposure of aircraft maintenance technicians to organophosphates from hydraulic fluids and turbine oils: A pilot study.” (2014) Int J Hyg Environ Health 217(1): 34-37.

141. Silverman, M.N., Pearce, B.D., Biron, C.A., et al. Immune modulation of the hypothalamic-pituitary-adrenal (HPA) axis during viral infection. (2005) Viral Immunol 18(1): 41-47.

142. Sledge, D., Yen, J., Morton, T., et al. A zebrafish model of the persisting neurobehavioral impairment caused by developmental chlorpyrifos exposure. (2009) Neurotoxicol Teratol 31(4): 242-242.

143. Slotkin, T.A, Seidler, F.J.F., Fumagalli, F. Targeting of neurotrophic factors, their receptors, and signaling pathways in the developmental neurotoxicity of organophosphates in vivo and in vitro. (2008) Brain Res Bull 76(4): 424-438.

144. SRI Consulting (SRIC). Worldwide FR consumption and geographical distribution. 2004. (1): 35-46.

145. Somkuti, S.G., Abou-Donia, M.B. Disposition, elimination, and metabolism of tri-o-cresyl phosphate following daily oral administration in Fischer 344 male rats. (1990) Arch Toxicol 64(7): 572-579.

146. Somkuti, S.G., Lapadula, D.M., Chapin, R.E., et al. Testicular toxicity following oral administration of tri-o-cresyl phosphate (TOCP) in roosters. (1987a) Toxicol Lett 37(3): 279-290.

147. Somkuti, S.G., Lapadula, D.M., Chapin, R.E., et al. Time course of the tri-o-cresyl phosphate-induced testicular lesion in F-344 rats: enzymatic, hormonal, and sperm parameter studies. (1987b) Toxicol Appl Pharmacol 89(1): 64-72.

148. Somkuti, S.G., Lapadula, D.M., Chapin, R.E., et al. Reproductive tract lesions resulting from subchronic administration (63 days) of tri-ocresyl phosphate in male rats. (1987c) Toxicol Appl Pharmacol 89(1): 49-63.

149. Somkuti, S.G., Lapadula, D.M., Chapin, R.E., et al. Light and electron microscopic evidence of tri-o-cresyl phosphate (TOCP)-mediated testicular toxicity in Fischer 344 rats. (1991) Toxicol Appl Pharmacol 107(1): 35-46.

150. Somkuti, S.G., Tilson, H.A., Brown, H.R., et al. Lack of delayed neurotoxic effect after tri-o-cresyl phosphate treatment in male Fischer 344 rats: biochemical, neurobehavioral, and neuropathological studies. (1988) Fundam Appl Toxicol 10(2):199-205.

151. Reinen, J., Nematollahi, L., Fidder, A., et al. Characterization of human Cytochrome P450s involved in the bioactivation of tri-ortho-cresyl phosphate. (2015) Chem Res Toxicol 28(4): 711-721.

152. Rossi, J.III., Jung, A.E., Ritchie, G.D., et al. Tissue distribution, metabolism, and clearance of the convulsant trimethylolpropane phosphate in rats. (1998) Drug Metab Dispos 26(11):1058-1062.

153. Rossi, J.III., Ritchie, G.D., Buring, M.S., et al. Chemical kindling of EEG epileptiform but not behavioral seizure response in two rat strains. (1994) Soc Neurosci Abstr 20:1459.

154. Rossi, J.III., Ritchie, G.D., Narayanan, T.K., et al. Clinical and subclinical seizure by trimethylolpropane phosphate. (1993) Soc Neurosci Abstr 9: 603.

155. Saboori, A.M., Lang, D.M., Newcombe, D.S. Structural requirements for the inhibition of human monocyte carboxylesterase by organophosphorus compounds. (1991) Chem-Bio Interact 80(3): 327-338.

156. Schulman, H. Advances in Second Messenger and Phosphorylation Research. New York: Raven Press, (1988) pp 39-111.

157. Sjödin, A., Carlsson, H., Thuresson, K., et al. Flame retardants in indoor air at an electronics recycling plant and at other work environments. (2001) Environ Sci Technol 35(3): 448-454.

158. Solbu, K., Thorud, S., Hersson, M., et al. Determination of airborne trialkyl and triaryl organophosphates originating from hydraulic fluids by gas chromatography-mass spectrometry. Development of methodology for combined aerosol and vapor sampling. (2007) J Chromatogr A 1161(1-2): 275-283.

159. Solbu, K., Daae, H.L., Olsen, R., et al. Organophosphates in aircraft cabin and cockpit air — method development and measurements of contaminants. (2011) J Environ Monit 13(5): 1393-1403. 
160. Smith, M.I., Elvove, E., Frazier, W.H. The pharmacological action of certain phenol esters with special reference to the etiology of so-called ginger paralysis. (1930) Public Health Rep 45(42): 2509-2524.

161. Sprague, G.L., Sandvik, L.L., Brookins-Hendricks, M.J., et al. Neurotoxicity of two organophosphorus ester flame retardants in hens. (1981) J Toxicol Environ Health 8(3):507-518.

162. Staskal, D.F., Diliberto, J.J., Birnbaum, L.S. Disposition of BDE 47 in developing mice. (2006) Toxicol Sci 90(2): 309-316.

163. Stapleton, H.M., Kelly, S.M., Pei, R., et al. Metabolism of Polybrominated Diphenyl Ethers (PBDEs) by Human Hepatocytes in Vitro. (2009) Environ Health Perspect 117(2):197-202.

164. Stapleton, H.M., Klosterhaus, S., Eagle, S., et al. Detection of Organophosphate Flame Retardants in Furniture Foam and U.S. House Dust. (2009) Environ Sci Technol 43(19): 7490-7495.

165. Sundkvist, A. M., Olofsson, U., Haglund, P. Organophosphorus flame retardants and plasticizers in marine and fresh water biota and in human milk.(2010) J Environ Monit 12(4): 943-951.

166. Sutton, W.L., Terhaar, C.J., Miller, F.A., et al. Studies on the industrial hygiene and toxicology of triphenyl phosphate. (1960) Arch Environ Health 1: 33-46.

167. Suwita, E., Lapadula, D.M., Abou-Donia, M.B. Calcium and calmodulin-enhanced in vitro phosphorylation of hen brain cold-stable microtubules and spinal cord neurofilament triplet proteins after a single oral dose of tri-o-cresyl phosphate. (1986) Proc Natl Acad Sci USA 83(16): 6174-6178.

168. Ta, N., Li, C., Fang, Y., et al. Toxicity of TDCPP and TCEP on PC12 cell: Changes in CAMKII, GAP43, tubulin and NF-H gene and protein levels. (2014)Toxicology Lett 227(3): 164-171.

169. Tabor, C.W., Tabor, H., Tyagi, A.K., et al. The biochemistry, genetics, and regulation of polyamine biosynthesis in Saccharomyces cerevisiae. (1982) Fed Proc 41(14): 3084-3088.

170. Tabor, C.W., Tabor, H., Tyagi, A.K., et al. The biochemistry, genetics, and regulation of polyamine biosynthesis in Saccharomyces cerevisiae. (1982) Fed Proc 41(14): 3084-3088.

171. Tagliaferri, D.S., Caglieri, A., Goldoni, M., et al. Low concentrations of the brominated flame retardants BDE-47 and BDE-99 induce synergistic oxidative stress-mediated neurotoxicity in human neuroblastoma cells. (2010) Toxicol In Vitro 24(1): 116-122.

172. Tanaka, D. Jr., Bursian, S.J., Lehning, E.J. Exposure to triphenyl phosphite results in widespread degeneration in the mammalian central nervous system. (1990) Brain Res 531(1-2): 294-308.

173. Tanaka, D. Jr., Bursian, S.J., Lehning, E.J. Neuropathological effects of triphenyl phosphite on the central nervous system of the hen (Gallus domesticus). (1992) Fundam Appl Toxicol 18(1): 72-78.

174. Tanaka, D.Jr., Bursian, S.J., Aulerich, R.J. Age-related effects of triphenyl phosphite-induced delayed neuropathy on central visual pathways in the European ferret (Mustela putorius furo). (1994) Fundam Appl Toxicol 22(4): 577-587.

175. Tanaka, Jr.D., Lin, M., Powell, D., et al. Effects of dark-rearing on triphenyl phosphate-induced neuropathy in the visual system of the developing European ferret (Mustela putorius furo). (1999) J Toxicol Environ Health 58(4): 215-231.

176. Staaf, T., Ostman, C. Organophosphate triesters in indoor environments. (2005) J Environ Monit 7(9): 883-887.

177. Timm, T., Marx, A., Panneerselvam, S., et al. Structure and regulation of MARK, a kinase involved in abnormal phosphorylation of Tau protein. (2008) BMC Neurosci 2: S9.

178. Tilson, H.A., Veronesi, B., McLamb, R.L., et al. Acute exposure to tris (2-chloroethyl) phosphate produces hippocampal neuronal loss and impairs learning in rats. (1990) Toxicol Appl Pharmacol 106(2): 254-269.

179. Tulve, N.S., Jones, P.A., Nishioka, M.G., et al. Pesticide measurements from the first national environmental health survey of child care centers using a multiresidue GC/MS analysis method. (2006) Enviroz Sci Technol 40(20): 6269-6274.

180. Umezu, T., Yonemoto, J., Soma, Y., et al. Tris(2-chloroethyl) phosphate increases ambulatory activity in mice. Pharmacological analyses of its neurochemical mechanism. (1998) Toxicol Appl Pharmacol 148(1): 109-116.

181. Child-Specific Exposure Factors Handbook (Final Report). (2008) US EPA p: 68.

182. Van der Veen, I., De Boer, J. Phosphorus flame retardants: Properties, production, environmental occurrence, toxicity and analysis. (2012) Chemosphere 88(10): 1119-1153.

183. Varghese, R.G., Bursian, S.J., Tobias, C., et al. Organophosphorus-induced delayed neurotoxicity: a comparative study of the effects of triortho-tolyl phosphate and triphenyl phosphite on the central nervous system of the Japanese quail. (1995) Neurotoxicology 16(1): 45-54.

184. Vora, D.D., Dastur, D.K., Braganca, B.M., et al. Toxic polyneuritis in Bombay due to ortho-cresyl-phosphate poisoning.(1962) J Neurol Neurosurg Psychiatry 25: 234-242.

185. Waaijers, S.L., Hartman, J., Soeter, A.M., et al. Toxicity of new generation flame retardants to Daphnia magna. (2013) Sci Total Environ 463-464: 1042-8.

186. Wang, Q., Lam, C.W., Man ,Y.C., et al. Bioconcentration, metabolism and neurotoxicity of the organophorous flame retardant 1,3-dichloro 2-propyl phosphate (TDCPP) to zebrafish. (2015) Aquatic Toxicology 158: 108-115.

187. Wang, Q., Liang, K., Liu, J. Exposure of zebrafish embryos/larvae to TDCPP alters concentrations of thyroid hormones and transcriptions of genes involved in the hypothalamic-pituitary-thyroid axis. (2013) Aquat Toxicol 126: 207-1.

188. Wei, G.L., Li, D.Q., Zhuo, M.N., et al. Organophosphorus flame retardants and plasticizers: sources, occurrence, toxicity and human exposure. (2015) Environ Pollut 196: 29-46.

189. Weingarten, M.D., Lockwood, A.H., Hwo, S.Y., et al. A protein factor essential for microtubule assembly. (1975) Proc Natl Acad Sci USA 72(5): 1858-1862.

190. Weiss, T., Schindler, B.K., Schütze, A., et al. Reply to the letter of Anderson J entitled "Comment on Schindler, BK; Weiss, T; Schütze, A; et al. Occupational exposure of air crews to tricresyl phosphate isomers and organophosphate flame retardants after fume events. Arch Toxicol (2013) 87: 645-648”. (2015) Arch Toxicol 89(2): 263-264.

191. Wensing, M., Uhde, E., Salthammer, T. Plastics additives in the indoor environment-flame retardants and plasticizers. (2005) Sci Total Environ 339(1-3): 19-40.

192. WHO, EHC 192: Flame Retardants: A General Introduction. (1997) Geneva Switzerland.

193. Wills, J.H., Barrona, K., Groblewskia, G.E., et al. Does triphenyl phosphate produce delayed neurotoxic effects? (1979) Toxicol Letters 4(1): 21-24.

194. Winder, C., Michaelis, S. Crew effects from toxic exposures on aircraft. (2005) Handbook of environmental chemistry 4: 211-228. 
195. Wolschke, H., Sühring, R., Xie, Z. Organophosphorus flame retardants and plasticizers in the aquatic environment: A case study of the Elbe River, Germany. (2015) Environ Pollut 206: 488-493.

196. Zhao, X., Wang, H., Li, J., et al. The correlation between polybrominated diphenyl ethers (PBDEs) and thyroid hormones in the general population: a meta-analysis. (2015) PloS One 10(5): e0126989.

197. Zhou, T., Ross, D.G., DeVito, M.J., et al. Effects of short-term in vivo exposure to polybrominated diphenyl ethers on thyroid hormones and hepatic enzyme activities in weanling rats. (2001) Toxicol Sci 61(1): 76-82.

198. Zhou, T., Taylor, M.M., DeVito, M.J., et al. Developmental exposure to brominated diphenyl ethers results in thyroid hormone disruption. (2002) Toxicol Sci 66(1): 105-116.

199. Zoeller, R.T., Crofton, K.M. Mode of action: developmental thyroid hormone insufficiency - neurological abnormalities resulting from exposure to propylthiouracil. (2005) Crit Rev Toxicol 35(8-9): 771-781.

200. Thomas, R Zoeller., Amy L.S, Dowling., Carolyn T.A, Herzig. Thyroid hormone, brain development, and the environment. (2002) Environ Health Perspect 110(Supp1 3): 355-356.

Ommega Online Publishers

Journal Title: Journal of Environment and Health Science (JEHS)

Journal Short Name: J Environ Health Sci
Journal ISSN: 2378-6841

E-mail: environmentalscience@ommegaonline.org

Website: www.ommegaonline.org 